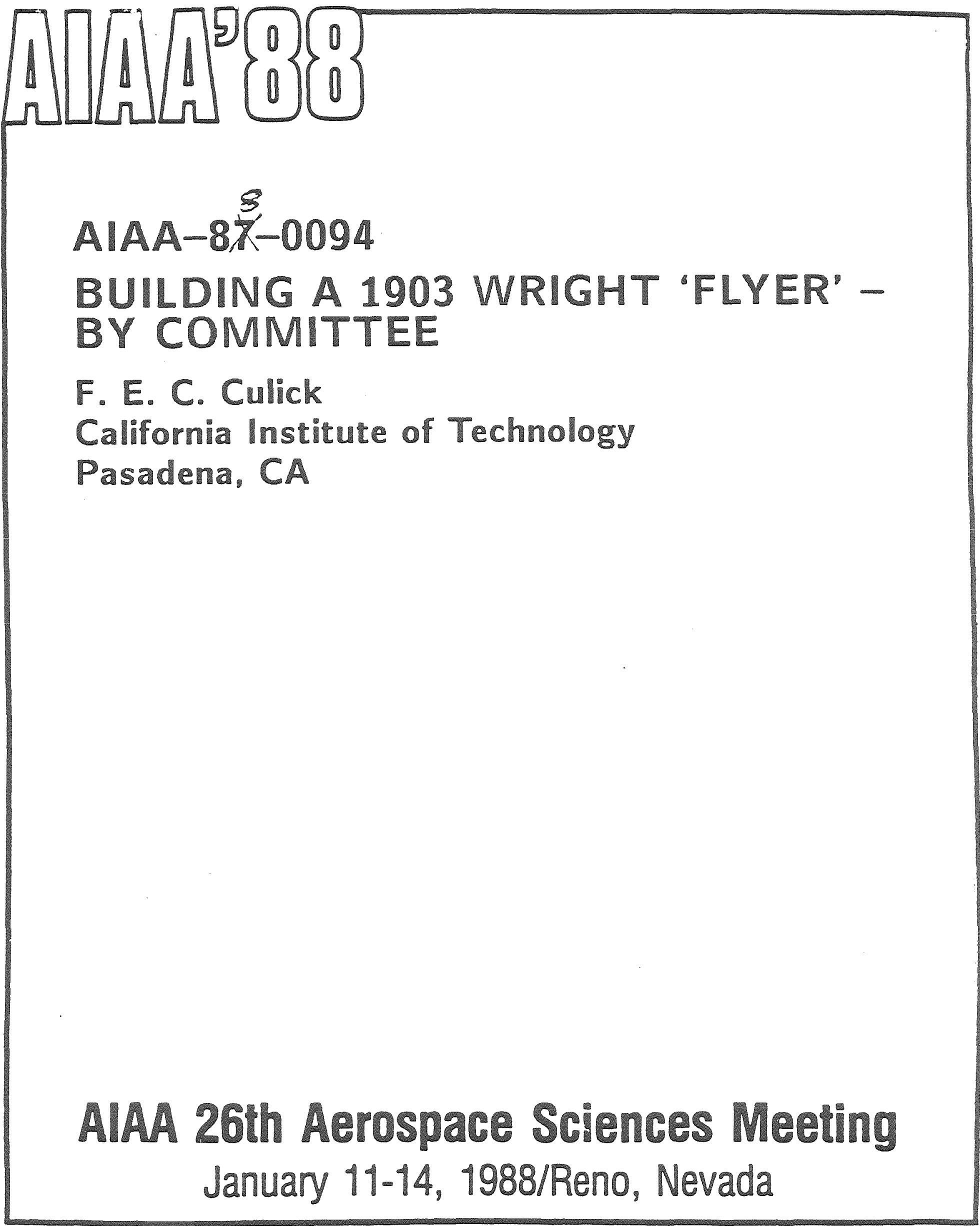

For pemlesion to copy or republish, contact the American Insthtute of Acrenautics and Astronautics 370 L'Entant Promenade, S.W., Washington, D.C. 20024 
NOTES 


\title{
BUILDING A 1903 WRIGHT 'FLYER' - BY COMMITTEE"
}

\author{
F. E. C. Culick**
}

California Institute of Technology

Pasadena, California 91125

\begin{abstract}
This is a summary of a lecture intended primarily as a progress report of the Los Angeles AIAA Section Wright Flyer Project. Begun in late 1978, the project is devoted chiefly to construction of two replicas of the 1903 Wright 'Flyer.' The first, now being covered, is an exact replica intended for full-scale wind tunnel tests. The second will be a fying replica, incorporating minimal modifications to produce a less unstar ble aircraft. Partly in preparation for the second aircraft, considerable attention has been given to the aerodynamics, stability, and control of the 1903 'Flyer.' Wind tunnel tests have been conducted with a $1 / 6$ flexible model, and a $1 / 8$ scale steel model tested at full-scale Reynolds numbers. The data have provided the basis for analyzing both the closed-loop and open-loop performance of the aircraft. Another aspect of the Project has been concerned with the history of early aeronautics, especially as related to the

* The Los Angeles AIAA Section has aupported this project with insurance funds collected after the destruction in 1978 of the 'Flyer' built by Section members in 1953. All labor has been provided by volunteer workers. The author's wind tunnel program with the $1 / 6$ scale model was supported by a NASA grant. Preparation of this manuscript has been supported in part by Caltech runds.

* Professor of Applied Physics and Jet Propulsion, Caliornia Institute of Technology; Fellow, A.I.A.A.

Copyright 1987 by F. E. C. Culick. Published by the American Institute of Aeronautics and Astronautics, Inc., with permission.
\end{abstract}

Wright Brothers' work. Thus a significant portion of the lecture is given to aeronautical history both before and after 1903, to provide a better appreciation for the Wrights' achievements and a clearer perspective of their work in the context of aeronautical progress.

\section{Introduction}

In the winter of 1978 , fire destroyed the San Diego Aerospace Museum. One of the airplanes lost was a replica of the 1903 Wright 'Flyer,' constructed in 1953 by the Los Angeles Section of the American Institute of Aeronautics and Astronautics (AIAA). Within a few months, the Section received the insurance claim, $\$ 20,000$.

As Chairman of the AIAA Committee on Special Events, Howard Marx of the Northrop Corporation proposed that a flying replica be constructed. The idea was enthusiastically accepted and the AIAA Wright Flyer Project was born late in 1978. Over the past nine years several dozen people have been involved, our plans have changed somewhat, and we still haven't flown our 'Flyer'!

Our plans have in fact expanded. We now intend to build two aircraft. One is an accurate full-scale rendition of the 1903 'Flyer' which will be tested in a wind tunnel. It is complete except for covering which was started last summer. The flying reproduction will have small changes from the original design to make the aircraft almost stable and easier to fly safely. Construction of the second aircraft has not begun.

Although the primary purpose of the project is to construct the full scale aircraft, other important activities have been pursued. Before 
the project was formed, I had already started building a $1 / 6$ scale model independently of the project. The National Aeronautics and Space Administration had granted me some financial support to construct the model and test it in the ten-foot wind tunnel at the California Institute of Technology. The test plan was later formulated as part of the project with the help of Dabney Howe (Northrop, Inc.) and Henry Jex (Systems Technology, Inc.). The data have been published as a Caltech report available through the project. ${ }^{1}$

Subsequently, several other members of the project built a $1 / 8$ scale steel model which was tested to nearly full-scale Reynolds numbers. Those tests produced extensive data which have not been completely processed, but already valuable information has been obtained. When the results are fully documented, they will constitute a valuable contribution to the history of aeronautics.

The wind tunnel data have been used in analyses of the dynamics, stability, and control of the aircraft. Some of the results have been published in a paper included in the proceedings of an anniversary symposium held at the National Air and Space Museum in December 1983. ${ }^{2}$ A shorter version was given at an A.I.A.A. meeting. ${ }^{3}$

Those publications represent a portion of our effort to provide technical documentation of the 1903 Wright 'Flyer'. Everybody involved in the project has had a serious interest in understanding the work of the Wright Brothers, all details of the airplane, and the historical contest in which their wonderful achievements took place.

The Rights of the 'Flyer' on December 17, 1903 were a remarkable achievement given little public notice at the time. While the Wrights rec- ognized the significance of being first to fly a controllable man-carrying powered flying machine, they knew that they had much to do before they would have a practical airplane. They worked for two years more until October 1905 when they were satisfied that they had their practical machine, one that they could market.

The Brothers then ceased flying and spent more than two years trying to reach satisfactory agreements to sell their invention. At last they signed contracts with a syndicate effectively representing the French government, and with the U.S. Army Board of Ordnance and Fortifications. As a result, in August 1908 Wilbur Wright gave the first public demonstrations of the Wright airplane, at the Le Mans, France. Two weeks later, Orville was the first to fly publicly a powered man-carrying aircraft in the United States, at Fort Myer, Virginia. Those astonishing fights were the beginnings of the Wrights' programs to fulfill the requirements of their two contracts. At the time, nobody else had a practical aircrait fully controllable and capable of being maneuvered at the pilot's command.

Yet within a year, France was clearly the leader in aviation. Blériot flew the English Channel in July 1909. For that dazzling accomplishment he gained Lord Northfield's Daily Mail prize in a highly publicized competition. Due to the press of other business Wilbur chose not to enter, even though he likely could have won easily.

The first international fying meeting, sponsored by the champagne industry and hence called "La Grande Semaine d'Aviation de la Champagne," was held in August 1909 near Reims, France. Again the Wrights elected to be absent, although three of their aircraft were entered, all flown by Frenchmen. Of the remain- 
ing 35 aircraft, one was designed and flown by the American Glen Curtiss and the rest were all French designs. Twenty-two aviators competed for eight days before two million people. French pilots flying French aircraft won all but three of the fourteen prizes; the three were won by Curtiss.

By the end of 1909, just six years after the Wrights historic 1903 flights, Frenchmen held most of the world's flying records for speed, altitude and distance. The French dominance in aviation did not diminish. During World War I, France produced more airplanes $(67,987)$ and lost more $(58,144)$ than any other country. The United States had 55 front line aircraft in 1914 and 740 in 1918, almost all French designs."

Those events in the two years 1908-1909 raise questions that merit attention. Why did the Wrights have a contract with the French, leading Wilbur to fly first publicly there while Orville showed their airplane in the U.S.? How did it happen that the French then not only became proficient in flying, but in fact quickly had their own superior designs? If, as apparently was the case, French aviation pioneers were prepared to exploit the new invention in ways which other countries were not, why was the U.S. and not France the birthplace of the powered mancarrying airplane?

The answers to those three questions are interrelated and follow as much from the styles of the inventors working in the two countries as on the state of aeronautics at the end of the nineteenth centrury. Because it moves in three dimensions, the airplane presents scientific and technological problems not previously encountered with vehicles moving on the earth's surface. Traditional methods of investigation successfully followed by inventors in the nineteenth century served poorly as the basis for solving the problem of mechanical flight. Major advances were necessary, both in understanding basic principles and in aeronautical technology. The Wrights' approach leading to the first practical airplane appears to us now as a fine - indeed, arguably the first - example of a modern program of research and development.

In contrast, the contemporary French aviation pioneers worked more in the fashion of trial and error with markedly less emphasis on determining the basic principles. Despite the obvious differences between the methods used and results obtained in the two countries, there was in fact a strong connection between the Wrights' work and the efforts of the aeronautical community in France. That connection did not give the French sufficient help for them to be first with a practical airplane, but it was a direct cause for Wilbur's appearance at Le Mans in 1908.

While the Wrights worked alone, the apparently rapid use of aeronautics in France after 1908 was actually the product of many years of work by a small enthusiastic community of inventors and experimenters. They were sustained in part by a few wealthy supporters and by their intense drive to make France the country that would give birth to the airplane. An influential member of that community, Ferdinand Ferber, established the first connections between American and French Aeronautics, and played a central role in the beginnings of powered flight in France. Among other achievements, Ferber made the first powered glides in Europe and was responsible for the aircraft configuration, widely used before 1910 , having both fore and aft horizontal tails. It was he who initiated correspondence with the Wrights in 1902, believed in their work and first urged the French government to buy the Wrights' 
aircraft. Although he did not ultimately participate in the negotiations with the Wrights, Ferber deserves major credit for helping French aeronautics to build on the Wrights' discoveries.

The Wrights kept detailed diaries, wrote many letters (copies of which they saved) and Orville took many photographs, especially in the period 1899-1905. Much of the material was collected in two volumes edited by Marvin McFarland. ${ }^{5}$ Those books contain sufficient technical details to understand the style of the Wrights and how they invented their airplane. What they accomplished becomes even more impressive in the context of aeronautical progress prior to the their program, and in striking contrast to the only other serious contemporary programs in France.

\section{Aeronautics in the Nineteenth Century}

The invention of the airplane was the result of international efforts spread over a century. ${ }^{7}$ In 1799, the Englishman Sir George Cayley (17831857) opened the modern era of aeronautics with engravings on a silver dise showing the basis for a fixed-wing aircraft. ${ }^{8}$ He realized that, in contrast to birds who use their wings both for propulsion and for lifting against gravity, the means for producing lift should be separated from the source of thrust required to overcome air resistance. On one side of the disc he drew a diagram of forces illustrating the idea. On the reverse side he sketched a fixed-wing aircraft. Five years later he constructed a model glider clearly recognizable as a device likely to fly stably. The tips of the wings were raised above the root, giving the dihedral angle that provides stability in rolling motions. It had an aft horizontal tail for pitch-

* Most of the material in this section has been extracted from reference 6. ing stability; and a vertical tail providing both directional stability and, according to Cayley's conception, steering. In addition to flying model gliders, Cayley is reported to have successfully tested a full-scale version carrying his coachman.

Cayley worked on the problem of flight throughout his distinguished engineering career. His contemporaries and followers in Great Britain adopted his ideas with only modest results and no fundamental advances in the technology. Without an adequate engine they could not succeed with powered flight and none tried gliding. Their efforts did, however, popularize the possibility of fying machines and contained some ideas that were later realized in practice.

Following Cayley, the next great advances were made in France by the aeronautical genius Alphonse Pénaud (1850-1880). He carried out fundamental researches on the forces experienced by bodies in motion and developed a thorough understanding of the problems which had still to be solved in order to achieve manned fiight.

For all his fundamental work in aeronautics, Pénaud is probably best known as the first person to use twisted rubber bands to power models. He constructed and flew model helicopters sustained by rotating wings; ornithopters which hew with flapping wings; and most significantly, in 1871, a fixed-wing model airplane with thrust provided by a propeller. The fixed-wing model was the first flying demonstration of an airplane having the modern configuration. Apparently Pénaud was at first unaware of Cayley's work and so re-invented the aft horizontal tail as a device for longitudinal stability. In a classic paper ${ }^{9}$ published in 1872 , he analyzed its operation, the first correct discussion of stability for an aircraft. As a result, the tail became known as the "Pénaud tail". His success with the stable pow- 
ered model subsequently caused almost all aviation enthusiasts, especially the French, to seek an inherently stable aircraft for manned flight. His ideas were influential long after his suicide at age thirty.

Pénaud's accomplishments were not surpassed until Otto Lilienthal (1848-1896) became the first man to fly repeatedly as master of his machine. Educated as a mechanical engineer in Germany, Lilienthal followed a long methodical program to solve the problem of mechanical flight. While a schoolboy, he and his brother Gustav had been inspired by birdflight to at tempt flying themselves by flapping mechanical wings.

The Lilienthal Brothers worked together on manned ornithopters for many years. Their failures finally led Otto to seek more basic understanding. He built a whirling arm apparatus for measuring aerodynamic forces and resolved to determine the airfoil shape having best rar tio of lift to drag. Quite naturally he tested shapes resembling the cross-sections of birds' wings, thereby excluding airfoils which were discovered later to be superior for fixed wing aircraft. That prejudice for thin highly cambered airfoil sections was copied by others almost universally until World War I. Aerodynamical theory and extensive laboratory tests then formed the basis for selecting more efficient airfoils. His book $^{10}$ Birdfight as the Basis of Aviation, thoroughly documents Lilienthal's research and flight test program.

Lilienthal's monumental achievements are twofold: he gathered the first quantitative data for the lift and drag forces on useful airfoils; and he designed, constructed and flew the first truly successful gliders, carrying him more than 300 yards in his best flights. His experimental data were subsequently used by the Wright Brothers in their initial designs, and independently mo tivated the first theory of airfoils invented by Kutta in 1902. His widely publicized gliding flights inspired first Octave Chanute and later the Wrights in the United States; Percy Pilcher in England; and Ferber in France. Lilienthal has justifiably been lauded by the French aviation historian Dollfus as "the father of modern aviation".

There can be no doubt that Lilienthal's greatest contribution to aviation was his public demonstration that manned flight was possible. He understood that learning the skill of flying was inseparable from the development of a successful airplane. In contrast, many of his predecessors and contemporaries took Pénaud's success to its extreme. They believed that an airplane could be built to fly so stably as to require the pilot merely to steer. Learning the skill of fying was not understood to be part of the problem. Lilienthal instinctively knew betm ter. He constructed and tested more than fifteen different glider designs. Near Berlin he built a dirt hill as a test site for launching his gliders in the direction dictated by the prevailing wind. The new technology of commerical photography dramatized the reports of his wonderful gliding flights. Pictures appeared in illustrated journals throughout Europe and the United States for several years in the mid-1890's. His death in 1896 from an injury suffered in a crash made international news.

The first in Europe to be inspired to his own flying experiments by the reports of Lilienthal's gliding tests was Percy Pilcher (1867-1899). After his discharge from the Royal Navy at aged 20 , Pilcher served as an engineering apprentice in several shipyards and in 1893 accepted a posi- 
tion as an assistant in naval architecture at the University of Glasgow. ${ }^{11}$ Two years later, having read of Lilienthal's work, he began his own flying program.

Although he had seen photographs of Lilienthal's gliders, all of which had horizontal tails, Pilcher determined to make his own design without a tail. He had no success. In the spring of 1895 he visited Lilienthal who convinced him that a horizontal tail was essential for stability. During the next four years Pilcher constructed and flew a succession of four gliders, the $B a t$, Beetle, Gull, and Hawk.

Pilcher made only modest progress in his work, but his best glides did exceed 250 yards. His other business activities prevented him from spending much time on his flying experiments. He had plans to build a powered aircraft, but his death in a crash of the Hawk in 1899 ended his program. Pilcher's work was not fundamentally different from Lilienthal's and he discovered no important new ideas.

Octave Chanute (1832-1910) was Lilienthal's second disciple. Born in France and raised in the United States, Chanute was a prominant civil engineer particularly well-known for his work on projects related to the development of railways in the midwest. He pursued a serious interest in aviation by traveling in Europe and the U.S., wherever necessary to speak with anybody actively trying to build airplanes, and writing articles. In 1894, the articles were combined and published $^{12}$ as Progress in Flying Machines. In that classic book, Chanute gave a thorough survey of aeronautics in the 19 th century, including discussions of the scientific and technological foundations of aeronautics, at the time very crude and poorly understood. Thus the book offers a particularly good basis for appreciating the inadequate knowledge of aeronautics available to inventors at the end of the 19 th century.

In 1895, imitating Lilienthal, Chanute began his own program of hang-gliding, with assistants doing the flying. He made no fundamental advances beyond Lilienthal and Pilcher, although he spent much effort unsuccessfully trying to devise an "automatically stable" glider that would carry a person in complete safety without the need for control by the pilot. Chanute's chief technical contribution to aeronautics was his adaptation of a bridge design, the Pratt truss, as the basis for his biplane configuration. The Wrights learned this structure from Chanute and adopted it for their aircraft. It became the standard structural design for all biplanes until cantilevered wings were used.

When Wilbur Wright (1867-1912) read of Lilienthal's death, his boyhood interest in fight was renewed. Joined by his brother Orville (1871-1948), in 1899 he began his work to build a flying machine. Their approach to the problem of flight was initially guided by Lilienthal's example, but from the beginning they added their own fundamental ideas and worked in their own style. For five years the Wrights pursued a systematic program of research, design, construction, and testing. Two years after they flew their first powered aircraft in December 1903, they had a practical airplane capable of fights as long as thirty-eight minutes (limited by the fuel supply) and under complete control at all times. It is a measure of the Wright's remarkable achievement that not until 1907 was anyone else (Farman, in France, flying a Voisin biplane) able even to exceed the duration of the Wrights' longest powered flight of 59 seconds in 1903 - and the airplane Farman flew was not fully controllable.

The competition to invent a practical air- 
plane was nowhere more intense than in France. A Frenchman had first risen into the atmosphere when the Montgolfier Brothers invented the hot air balloon and flew in 1783. Throughout the 19th century from Giffard to Renard to the Lebaudy Brothers and Santos-Dumont, the French led the world in historic advances of powered ballooning. By the end of the century, the dirigible - the name itself is French - seemed clearly to offer the best prospects for controlled flight. The French Artillery looked to the airship for scouting and reconnaissance. Societies meeting in France, as elsewhere to discuss aviation, were chiefly concerned with "aerial navigation", flight with lighter-than-air-craft.

Early experiments with heavier-thanaircraft in France came to an end with Ader's disappointing results ${ }^{13}$ : he had been able to achieve only a "tentative hop" with a crudely designed aircraft alternatives to balloon in 1890 . Nevertheless, the first European flying had happened in France and some members of the aeronautical societies still discussed helicopters, ornithopters and fixed-wing aircraft. Pénaud had been a proponent of the last, but even in France his influence did not make the airplane the obvious choice for solving the problem of mechjanical flight. For some unknown reasons, Lilienthal's gliding tests made essentially no contemporary impression in France. When Ferdinand Ferber entered aeronautics, the mainstream of French interest, particularly in the army, lay with airships.

The Problem of Mechanical Flight c. 1900

Even with the public favoring airships, the French aviation pioneers were working as a community in a supportive and fertile environment. Fundamentally their failure to beat the Wrights was due to their failure to formulate, understand and solve the technical problems.
Despite considerable discussion of the "problem of mechanical flight" during the years ending the nineteenth century, the "problem" was in fact not at all well-defined. Lilienthal, professionally a mechanical engineer, carried out a large number of tests to determine the lift and drag of airfoils having the profiles similar to the cross-sections of birds' wings. He then built his gliders using his best airfoil shape (i.e. that one having the highest lift/drag ratio). That was a sensible beginning, but the most difficult problems were associated with the configuration of the aircraft. Lilienthal adopted the geometry invented by Cayley. It was a good choice, and he made essentially no improvements. His chief contributions were the idea of control by shifting the pilot's weight; and, far more influential, the principle that to construct a successful airplane, the inventor must also learn how to fy. Although he must have given some thought to the matter, Lilienthal never offered an analysis of the mechanics of flight. He apparently never tried to attack the problems of lateral control and turning.

With his book Progress in Flying Machines, Chanute intended to provide a technical basis for constructing a man-carrying aircraft. Yet the best parts of his writings are descriptive, summarizing the history of the subject. Even with his background in engineering, Chanute did not pose the basic problems which had to be solved. One likely reason is that as a 19th century civil engineer, Chanute had not been well-educated in physics and mathematics.

Samuel P. Langley (1834-1906) tried to follow a more fundamental strategy. Beginning in the 1880's while he was Director of the Allegheny Observatory, he set out to discover the "principles of flight" by conducting a series of tests to 
measure aerodynamic characteristics. ${ }^{14}$ Unfortunately, he resolved to learn all he could about the performance of one airfoil section, and he chose the worst possible case to study: a flat plate. For all his effort and expense, Langley obtained only one useful correct result, the drag of a plate oriented normal to the stream. His experiments contributed nothing to aeronautics, including his own program.

For ten years while he was Secretary of the Smithsonian Institution, Langley spent $\$ 50,000$ given to him by the U.S. Army, and at least $\$ 20,000$ of his own discretionary funds, on his aeronautical work. He tested powered models, commissioned the design and construction of a light internal combustion engine, and finally attempted twice to fly a full-scale aircraft carrying a man. ${ }^{15}$ Both trials were highly publicized fail ures in the fall of 1903. Langley's results convinced government officials worldwide that public funds must not be wasted on schemes to invent airplanes.

Langley's plans may seem to have been systematic, but there were serious gaps. The major reason that he did not succeed with his full-sized airplane was his failure to apply Lilienthal's principle. His assistant and intended pilot, Charles Manly, had no opportunity to learn how to fly in gliders before testing the powered airplane. Langley the physicist didn't appreciate the difference between experimenting to solve a well-defined but narrow problem, and the extended research and development program required to produce a practical engineering system. Somewhat surprisingly, he also did not try to analyze the mechanics of flight except for superficial consideration of equilibrium. He did not progress beyond the results of Cayley and Pénaud. Like Lilienthal, he never considered lateral control and evidently thought his airplane could be turned by manipulating the vertical tail.

Prior to the twentieth century, only the Englishman Frederick Lanchester (1878-1946) studied flight mechanics. Motivated by his observations of model airplane tests, Lanchester worked out many fundamental results, including the essential basis for early wing theory. His work was unknown until his two books ${ }^{16}$ appeared in 1907 and 1908 and so had no impact on the invention of the airplane. Even had he published his results, they would have had limited value for someone concerned with the practical problems of building the first flying machine. During his early work, Lanchester too was concerned only with pitching notions.

Thus at the turn of the century, there was almost no theoretical basis for designing an airplane. The issue was not merely that known problems were unsolved; rather, the greatest difficulty was that several crucial problems had not even been addressed: the right questions had not been asked. In that respect, the Wrights' pro gram and the halting efforts of the French in the period 1898-1908 present startling contrasts. The disappointing experiences of Ferber and others in France emphasize the obstacles to solving the problem of mechanical flight and further justify deep admiration for the Wrights' success.

The problem of inventing the powered mancarrying aircraft may retrospectively be divided into four pieces: basic aerodynamics; structure; propulsion system; and configuration or geometry. At the end of the 19th century the first three matters had almost reached satisfactory states. One hundred years earlier Cayley had separated the problems of generating lift and thrust and already knew the essentials of basic aerodynamics. He had enough data for the lift and drag on an 
airfoil to proceed with his gliders. Later workers, notably Lilienthal, did not substantially advance the fundamental understanding of aerodynamics. When they began their work, the Wrights had entirely adequate data for the lift and drag of usable airfoil sections, thanks chiefly to Lilienthal's experiments.

Most of the materials and details of structural design for early aircraft were adapted from existing technologies for ships, bridges, and kites. Although there are many clever and innovative details in their 1903 airplane, the Wrights primarily used existing techniques. It is worth noting, however, that their craftsmanship was superior to that of most of their contemporaries.

During the last quarter of the 19 th century, the invention of the four-stroke cycle internal combustion engine, burning liquid fuel, finally gave a superb powerplant. The weight to power ratio was reduced from 4000 pounds per horsepower for the typical steam engine in the 1870's to 4 for the best internal combustion engine available in the early 1900's. Pro peller design was not understood, however, and the Wrights greatest analytical achievement was their construction and application of blade element theory. Their results (which they never published) allowed them to make propellers having efficiencies more than $70 \%$ at a time when others could achieve only 50\%. That considerable advance was essential to their successful flights in 1903 but it was not the central matter in their invention of the airplane.

Put most simply, the Wrights' basic discovery consisted in determining the geometry of a successful airplane. To reach that conclusion required a systematic program of designing, building, testing and learning how to fly. Geometry here means not merely the spacial arrangement of the basic flying surfaces but also those special features enabling the pilot to control the machine. Thus their geometry directly reflected the principles of mechanical flight which the Wrights understood, principles that none of their contemporaries had been able to discover.

Cayley knew the geometry of the fixed wing aircraft in essentially the form now familiar: for that discovery he has properly been called the "inventor of the airplane". Why then did a hundred years pass before a successful man-carrying airplane was flown? Part of the answer is due to the absence of a suitable powerplant. But even so, gliders could have been constructed, as Cayley himself demonstrated and later Lilienthal and the Wrights proved. In view of the earlier work by others, the configuration chosen by the Wrights is particularly surprising. Their canard configuration, with no aft horizontal tail, was not at all suggested by earlier work and indeed was entirely contrary to the commonly understood function of the Pénaud aft tail.

There is no doubt that the Wrights' experience with bicycles taught them to be satisfied with a controllable machine, even though it might be unstable. That acceptance already set them apart from all other previous and contemporary aeronautical experimenters. The only principles of flight mechanics known (albeit crudely and incompletely) at the end of the 19 th century concerned equilibrium and stability of pitching motions, i.e. motions in the plane of symmetry of an aircraft. Even so, the motions of equilibrium and stability had not been carefully formed and the precise conditions for making an airplane trimmed and stable were unknown.

The fundamental condition for a state of pitch equilibrium was understood by Cayley and all who followed him: the center of lift must co- 
incide with the center of gravity. Otherwise the lift force exerts moment tending to rotate the aircraft. Further, for an aircraft symmetric about a vertical plane - always implicitly assumed the center of lift and center of gravity both lie in the plane of symmetry. If the perfect symmetry is maintained, there will be no tendency in steady flight for the aircraft to roll about its longitudinal axis and the wings will remain level. Those remarks summarize the idea of equilibrium known in 1900 .

If the aircraft does not change shape in flight, and there is no movement of its parts, tre center of gravity remains in a fixed position. Hence, a condition of steady flight in equilibrium is conceivable if the wing and other surfaces are so placed as to cause the net force to act precisely at the center of gravity. That is a delicate state due to the fact that the center of lift on a surface depends on the angle of attack.

The early aircraft designers were aware that the center of lift may shift during fight, but they understood neither the details, nor the important fact that the behavior is sensitive to the shape of the airfoil. Obviously, if equilibrium requires that the center of lift and center of gravity must coincide, then to accommodate large disturbances, some means of control must be found to maintain equilibrium in the face of changing flight conditions. There are two choices: either adjust the center of gravity, or incorporate an aerodynamic method for forcing the center of lift to remain at a fxed location. Lilienthal chose the former: he suspended himself from the structure and was able to move his body relative to his glider, so he could actively shift the center of gravity of the combined pilot/airplane during flight. The Wrights took the revolutionary step of installing a surface that the pilot could move at will, thereby controlling the movement of the center of lift of the aircraft.

Throughout early aeronautics there was confusion between the ideas of equilibrium and stability. Both Lilienthal and the Wrights were trying to maintain equilibrium during flight by providing the pilot with a means of control; stability was a secondary issue, particularly for the Wrights. But Cayley had long before shown that a glider could be constructed to fly by itself, and Pénaud had successfully flown a powered model for flights of many seconds. Those devices were surely subject to disturbances during their flights and hence must somehow have been able to compensate automatically in such a fashion as to assure coincidence of the center of lift and the center of gravity.

To illustrate the idea of stability and how equilibrium is maintained, suppose first that a small wing is launched on an intended glide: it tumbles and falls spinning about its long axis. That distressing result is due to the fact that the surface developes not only lift but also a pitching moment. It is impossible to make a wing alone glide smoothly unless the moment is zero. Flying wings do exist, but the airfoil must be shaped with a reflexed trailing edge, a property discovered in 1906 by a Canadian physicist, W. R. Turnbull. ${ }^{17}$ However, Cayley, Pénaud, Lilienthal and all others trying to build early aircraft used airfoils formed roughly as they interpreted birds' wings. A horizontal tail is then essential. If the tail is set at the proper angle, the center of lift of the combined wing and tail will coincide with the center of gravity. There is therefore no resultant aerodynamic moment, and the configuration may glide in equilibrium.

But what happens if there is a disturbance? For example, if the glider encounters an upward 
gust of wind, the wing suddenly experiences an increase in angle of attack, its lift increases and worse, its center of lift moves forward. To restore equilibrium, the lift on the tail and its center of lift must respond in just the right way to cancel the incremental change of moment due to the wing. It was the remarkable perception of both Cayley and Pénaud that a horizontal tail will do just that. Automatic restoration of equilibrium is called stability. Pénaud gave a partial explanation of this mechanism and published his results in 1872.9 His conclusions were well-known in the aeronautical communities in all countries.

A Pénaud tail can provide both equilibrium and stability. Lilienthal built his gliders with aft tails and they were probably capable of stable flight without a pilot. However, he introduced the further notion of control by the pilot swinging his body, so the combination of glider and pilot was stable even under circumstances when the glider alone might be unstable. His means of control was so limited that his machines had to be stable, or very nearly so. Shifting his weight was chiefly a means of combating disturbances in unsteady winds and was effective only if the disturbances were not too large.

The Wrights' system of using a moveable control surface allowed their aircraft to be unstable alone. Indeed, all their early aircraft were seriously unstable and could be operated only by skilled pilots. Mainly because of their experience with bicycles, the Wrights were comfortable with a machine that was always unstable - so long as they had enough control. Consequently they were also not driven to use the aft tail just because it was accepted practice. They put the tail in front - the canard - because their two immediate predecessors, Lilienthal and Pilcher, had both been killed flying gliders with aft tails.
They believed that they could have more effective control with their canard, and besides they could see what the surface was doing in Hight. That their aircraft were unstable was not a necessary consequence of their geometrical configurations. Neither they nor any of their contemporaries truly understood the notion of stability. The Wrights were unaware of the fact that the canard configuration can be made stable if the center of gravity is properly positioned.

Just as for pitching motions, we must distinguish equilibrium, stability, and control of lateral motions. The term 'lateral motions' refers both to rolling - the wing rotates about the direction of forward motion - and to yawing, in which the nose swings right and left. Stability of yawing motions, or directional stability, is provided by a vertical aft tail. The idea is simple: the vertical tail on an airplane acts in exactly the same way as the feathers on an arrow cause its flight to be straight. If the arrow should swing to the right or left, the feathers are then oriented at an angle to the direction of motion. Thus a small force is generated in just the right direction to rotate the arrow so it points in the intended direction.* On an airplane, a portion of the vertical tail is made

- Similarly, a vertical surface at the front of the arrow is destabilizing. One might therelore conclude that a horizontal aft tail is stablizing and that a canard must be destabilizing. Early aviation pioneers may have used that argument as a reason for not building aircraft with canards. However, actions of a forward vertical tail and a canard are not analogous because a horizontal tail is always used with wing. Stability in pitch depends on the infuences of both surfaces and is therefore significantly different from stability in yaw with a single vertical suriace. Because the Wrights regarded the canard solely as a control surface, they were not concerned with its 
moveable so the pilot can have control over yawing motions. It is important to realize that the vertical tail is not properly used to steer an airplane. To turn an airplane, the pilot first causes it to roll, so one wing tip is lower than the other, a maneuver which the Wrights discovered. That was crucial to their invention.

An aerodynamic force perpendicular to the flight path is required to maintain a turn. The necessary force is quite large and is best obtained by tilting the vertical lift force so that a portion acts in the direction of the desired turn. Because the lift is perpendicular to the wing, the wing itself must be tilted, or banked. To initiate a turn, the pilot therefore operates the ailerons, or wing warp, so as to roll the airplane into the suitable bank angle. It is true that with the addition of special control surfaces, sufficient side force can be generated to tum an aircraft without rolling. A disadvantage is that this kind of maneuver is also accompanied by a sideways acceleration, very uncomfortable for occupants of the vehicle, so almost all airplanes are turned by banking.

Equilibrium and stability are as important for rolling as for pitching but easier to achieve. During steady flight with wings level, an aircraft having a plane of symmetry is in a condition of equilibrium in roll. That stability in roll is so simply accomplished is likely a major reason that the need for control of rolling motions was overlooked by all aviation pioneers prior to the Wrights. Cayley discovered that if the wing is made with a slight dihedral angle, so its tips are higher than the center section, small disturbances will be compensated automatically and the surface will be stable. One way to see this is

possible contribution to pitch stability, which in any case they didn't really understand. to form a shallow cone out of paper. Dropped with the point down, the cone falls smoothly. But if the cone is dropped with the point up, it will quickly tumble and assume the stable orientation. With care, one may draw the same conclusion from tests with a strip of paper folded in the center to form a dihedral angle: if it is released with the point of the vee downward, it tends to fall more smoothly than in the inverted position.

The preceding remarks explain why uncontrolled model airplanes - which must have automatic stability - have their familiar geometry. A horizontal tail is located some distance forward or aft of the wing, for pitch equilibrium and stability. The vertical aft tail provides directional stability; and the dihedral angle of the wing gives stability in roll. Satisfactory glides can be obtained with a device having this geometry, providing the center of gravity is correctly placed. Tests with a model glider often show that best performance is obtained if a bit of weight is added to the nose of the glider. The reason is that stability is improved when the center of gravity is moved forward. That property of all aircraft is more difficult to understand and was a continual source of problems with early aircraft which were commonly unstable, even to the point of being dangerous.

By trial and error the Wrights eventually found that their aircraft became less unstable if the center of gravity was shifted forward, but they did not know the theoretical reason. Coincidentally, a few months before the Wrights' flights in 1903, the first complete analysis of pitch stability was published ${ }^{18}$ by G.W. Bryan, a Pro fessor of Mathematics at the University College of North Wales, and his student W. E. Williams. That was the first work in which the equation 
of pitching moments was written for an aircraft. Bryan and Williams showed how gliders with either aft tails or canards could be made stable. The work was unknown to the Wrights and to all other constructors of aircraft for several years, and only gradually influenced aircraft design. In 1911 Bryan produced a small volume ${ }^{19}$ Stability in Aviation that founded the theory of aircraft stability in essentially its present form.

Cayley had found the correct geometry of an aircraft, but he did not thoroughly understand the physical basis. Among his small number of followers, only Pénaud made significant progress; even he did not appreciate the further advances required to build a successful man-carrying airplane. Not until the early years of the 20th century were the missing ideas supplied, primarily by the Wrights. The chief reason that the solution to the problem of mechanical fight was so difficult to find is that an aircraft moves in three dimensions. Its motions involve not only translations horizontally, vertically and sideways, but also rotations about the three axes of pitch, roll, and yaw. With only aerodynamic forces available to compensate the pull of gravity, the problems of equilibrium, stability and control are vastly more complicated for aircraft than for vehicles moving on the earth's surface.

Today we have a complete theory of aircraft fight. In the 19 th century, not only was information about aerody namics sparse, but there was no theoretical framework for understanding the mechanics and dynamics of aircraft. The fundamental physical theory - Newtonian mechanics - of course existed, but until Bryan began his work, no one had made even the most elementary attempt to analyze the motions of an aircraft in pitch. Pénaud's explanation of the aft horizontal tail was correct but qualitative and did not suggest the general nature of stability.

Consequently, the aircraft inventors, who generally lacked backgrounds in physics and mathematics, progressed by trial and error. Success then depended entirely on their own tests, observations, reasoning and insight. It's a tedious procedure. Ferber and the French aviators discovered that failure is the more likely result.

The Wrights' Work 1899-1903*

When they began their experiments, the Wright Brothers had read the available aeronautical literature and thoroughly understood all previous work. It was not from ignorance that they often deviated from accepted practice; their technical decisions were always soundly based on their own experience and reasoning. As a result, the configuration of the 1903 'Flyer' was not a logical consequence of aeronautics in the 19th century; it was the revolutionary conclusion of the first aeronautical research and development program in the 20th century.

In May 1900, Wilbur wrote to Octave Chanute that "my observations of buzzards leads me to believe that they regain their lateral balance, when party overturned by a gust of wind, by a torsion of the tips of the wings".

That idea was the beginning of the Wrights' technical work and clearly displays the central theme of their invention - control. Since Cayley introduced dihedral as a passive means for giving stability in roll, nobody had considered any other possibility.* That equilibrium should be maintained by actively controlling roll motions

\footnotetext{
- Most of this section is taken from reference 20 .

* Moveable suriaces on the wing were proposed in patents granted in England to Boulton (1859) and Harte (1870). However, the devices were intended for pitch control.
} 
was a startling new idea.

Wilbur realized that he could imitate the birds' method of roll control by warping a flexible wing. He soon discovered that he could conveniently build a structure with wing warping by modifying Chanute's adaptation of the Pratt truss. He then built a biplane kite of that design, spanning five feet (Figure 1). For control in pitch he attached a small horizontal surface. That device was the first flying machine having control about the pitch and roll axes.

One day's tests in August 1899 convinced Wilbur that his ideas of control were correct. The kite would rrobably have been unstable in both roll and pitch if flown freely as a glider; there is no record that Wilbur tried such tests. If instabilities appeared in the kite tests, they were controllable. The kite was successfully flown with the horizontal surface forward or aft.

The strategy was then to scale up the kite to a size sufficient to carry a man. It could then be flown tethered as a kite, with a pilot on board, or freely as a glider. For those tests, a strong steady wind was desireable. On recommendation from the Weather Bureau, the Wrights chose the area known as Kill Devil Hills, near Kitty Hawk, as the location of their test facilities. The 1900 kite/glider, shown in Figure 2, had a span of 17 feet, chord of 5 feet and weighed 190 pounds with pilot, giving a wing loading of 1.15 pounds per square foot.

Using Lilienthal's data for lift and drag, the Wrights set the size of the glider by assuming a nominal flight speed and requiring that the lift be sufficient to sustain the total weight of pilot and structure. To get an answer, they also had to assume a value for the angle of attack, which would then determine the values of the lift and drag coefficients. What calculations they actu- ally did cannot be determined from the papers available, but in any event two things are clear: (1) this was the extent of their analysis of performance for their design; (2) the calculations are incomplete and could have given realistic results only if the required input values were guessed accurately.

With experience, the Wrights may have learned how to make realistic estimates of the performance of their gliders and, later, their powered aircraft. Equally, they gathered sufficient data from tests to make desired changes without relying heavily on any analysis; any claims they made for projected performance must always have been inferred from their previous test results. The reason for those conclusions is again that, like all of their predecessors and contempo raries building aircraft, the Wrights never dealt quantitatively with the moments acting on their aircraft. In particular, they never wrote an equation for the pitching moment, a failure that prevented any proper analysis of performance stability or control. That nobody (except Lanchester in a limited fashion and later Bryan who did a thorough job) studied the problem of moments acting on a aircraft is arguably a major reason that a practical aircraft was not invented sooner.

To be specific, consider the elementary problem of steady gliding. There are three unknowns: the glide speed, the angle of attack and the fight path angle. The three equations to be solved are those for the forces parallel to the fight path; the forces normal to the flight path; and for the pitching moment. Effects of geometry, including elevator deflection, of course enter explicitly in the equations. With no equation of moments, the Wrights could not solve the problem without guessing one of the unknowns. The Wrights, as remarked above, were really just following the 


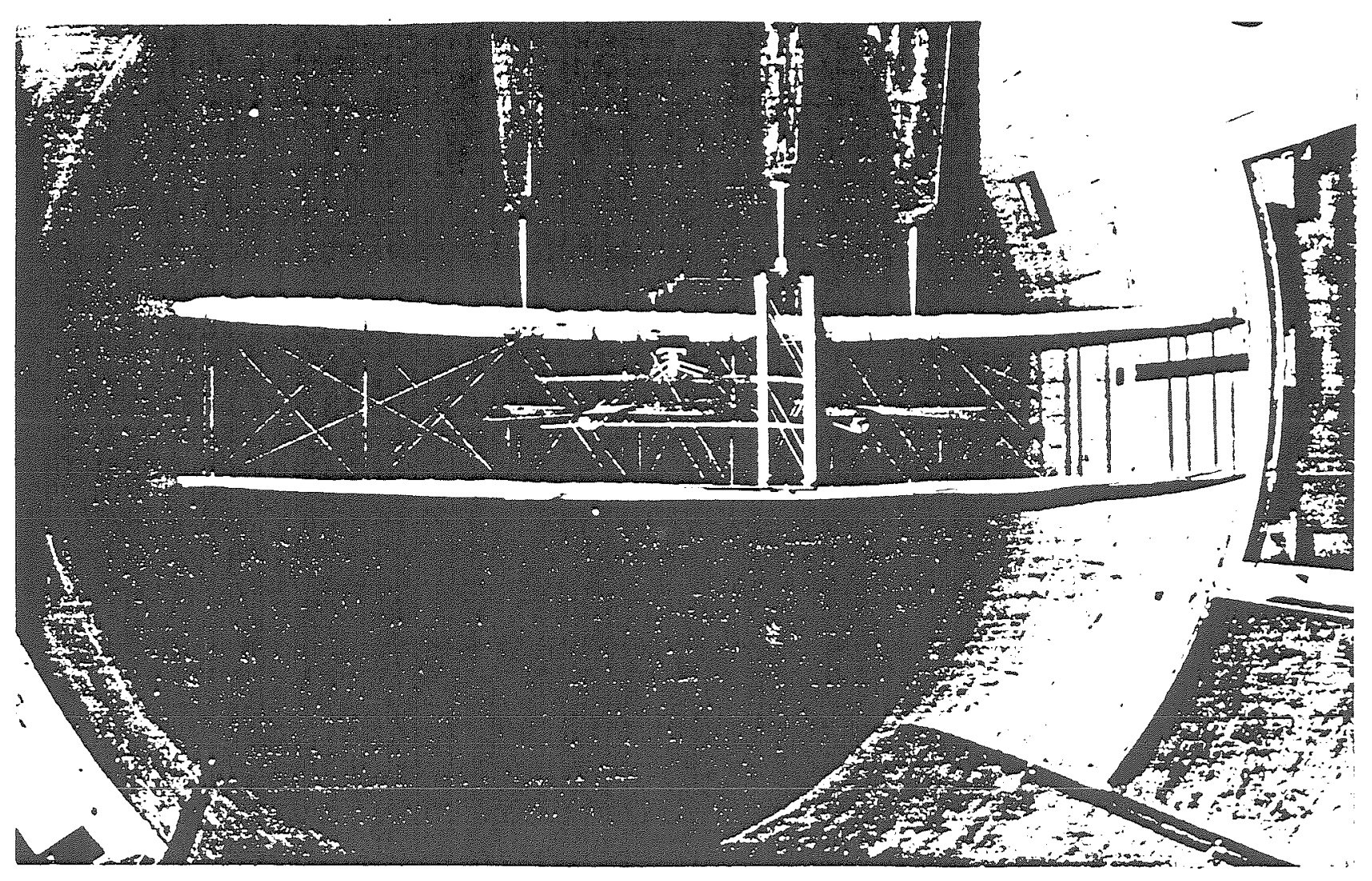

Figure 12. 1/6 Scale Model in GALCI Ten-Foot Tunnel

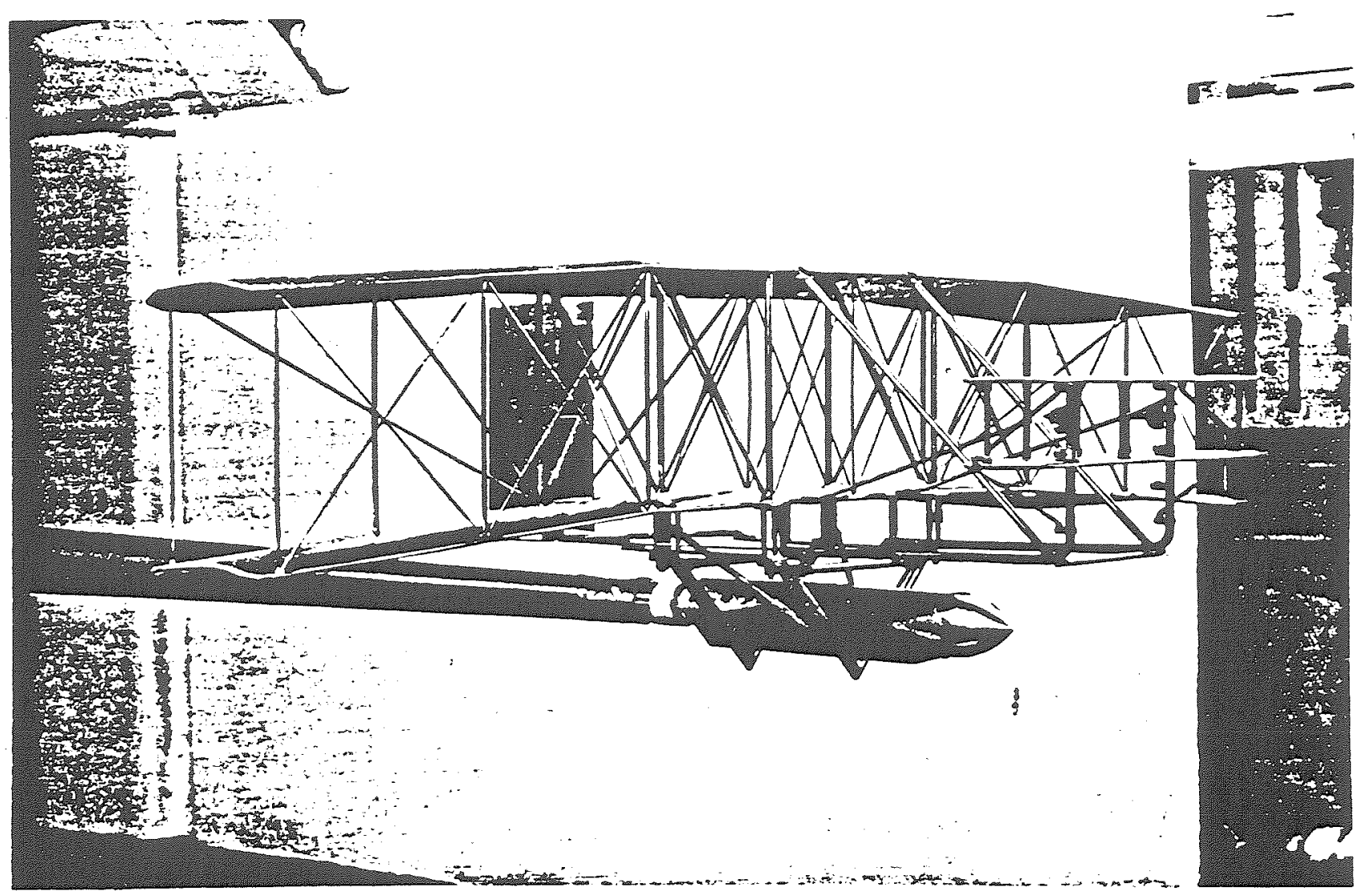

Figure 13. 1/8 Scale Stainless Steel Model 


\section{LEGEND:}

Vortex-latice theory (Dwyer 1981)

$\multimap$ Sleel model of RN $=.90 \times 10^{6}$ (Heglund 1983)

$\times \times \times$ Covered model of $R N=.43 \times 10^{6}$ (Culick 1982)
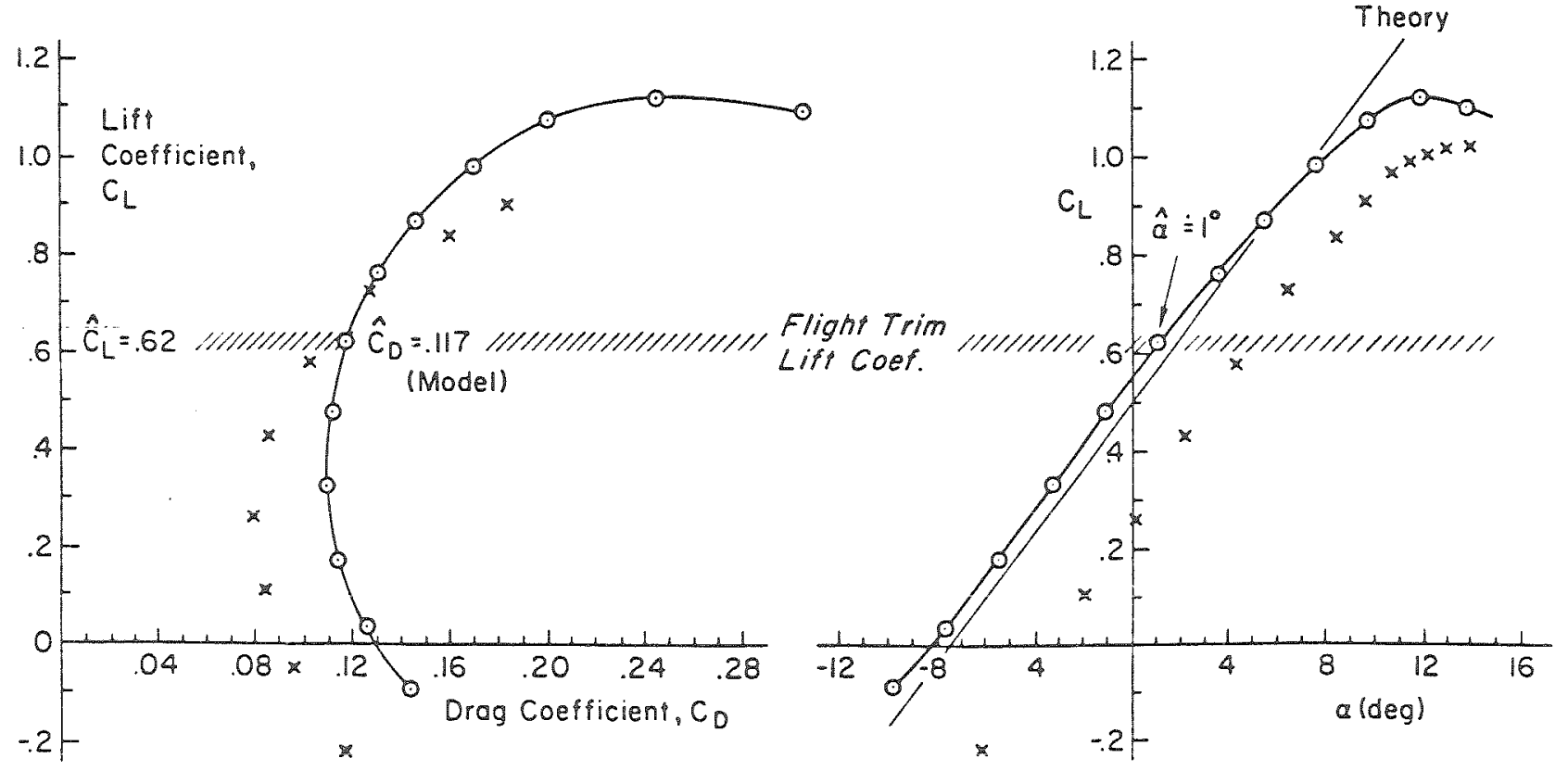

Figure 14. Lift and Drag for 1903 Flyer: Comparison of Theory and Data

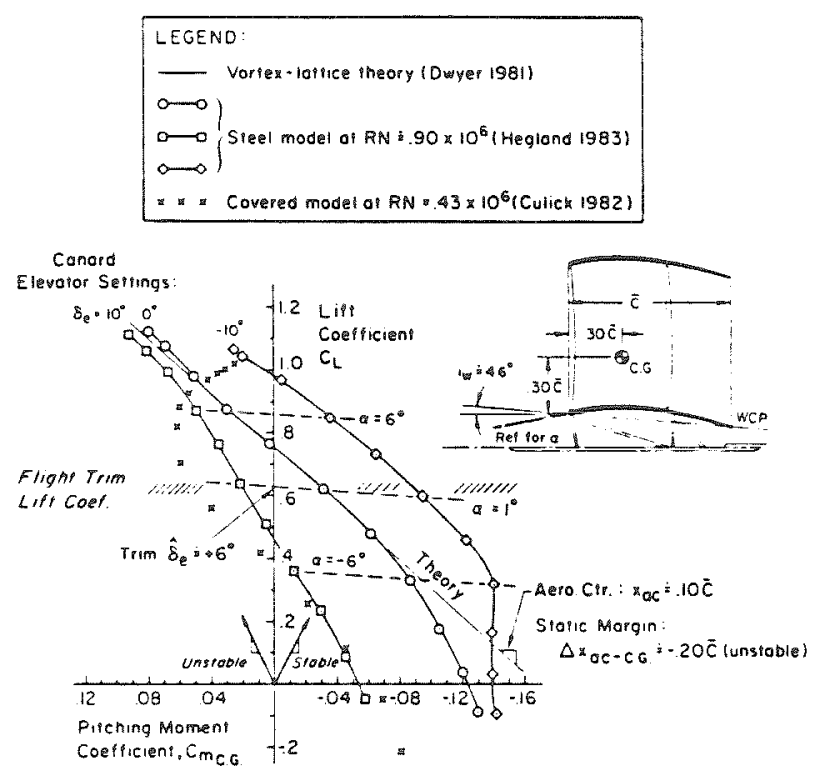

Figura 15. Futcing Nonent of the 1903 Flyer: Comparison of Theory and Data 


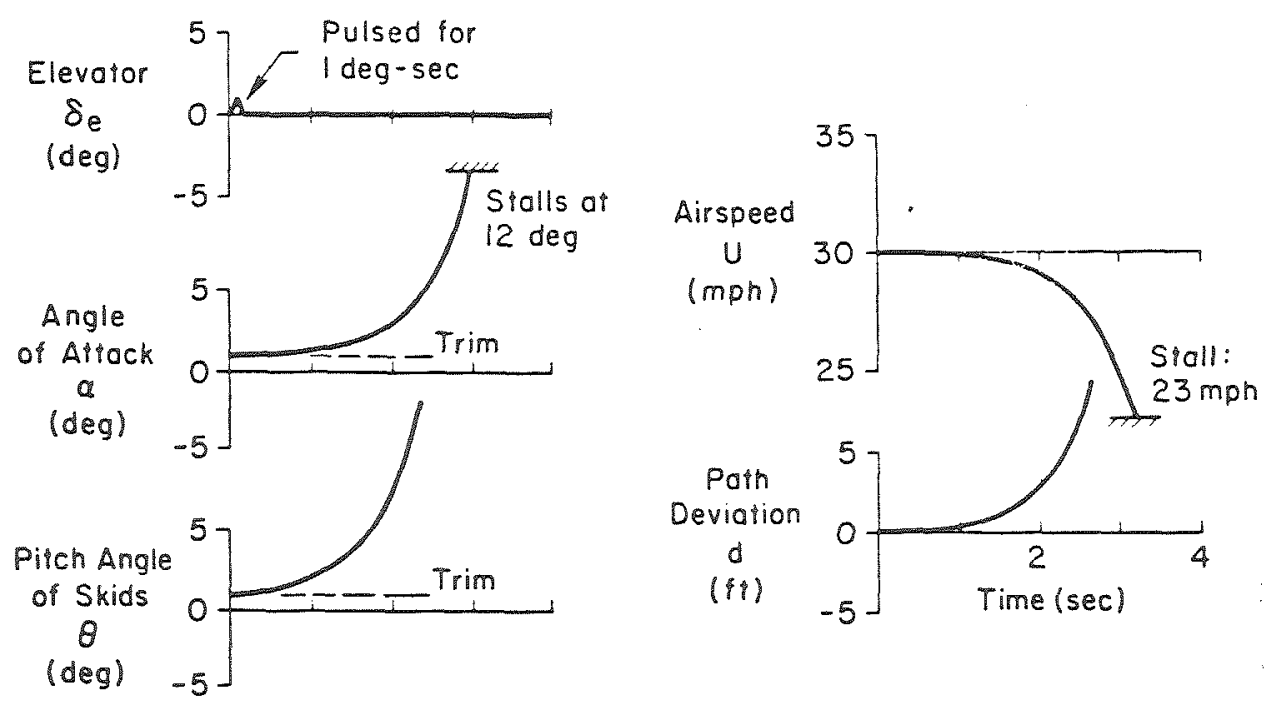

Figure 16. Open Loop Time Response in Fitch, one Degree Pulsed Canard Deflection

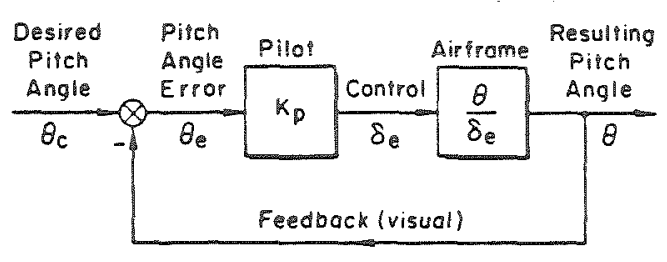

Open Loop:

$$
\begin{aligned}
& \text { Loop: } \quad M 8_{\varepsilon} \quad 1 / T_{\theta_{1}} \quad 1 / T_{\theta_{2}} \\
& \frac{\theta}{\theta_{e}}=Y_{D} \cdot Y_{B_{e}}^{\theta}=K_{D} \frac{11.0(s+.5)(s+3.0)}{\left[s^{2}+2(.30)(1.2) s+1.2^{2}\right](s-1.7)(s+7.0)} ; K_{p} \quad 0 p t=4.0 \\
& \zeta_{p}, \omega_{p} \\
& \text { Phugoid Mode } \\
& 1 / T_{S P_{1}} \quad 1 / T_{S P_{2}} \\
& \text { Short Period Modes }
\end{aligned}
$$

Closed Loop:

$$
\frac{\theta}{\theta_{c}} \doteq \frac{(s+5)(s+3.0)}{\left[s^{2}+2(10)(5.5) s+5.5^{2}\right](s+.33)(s+4.6)}
$$

Closed loop poles for $K_{p}=4.0$ deg conord/deg pitch error
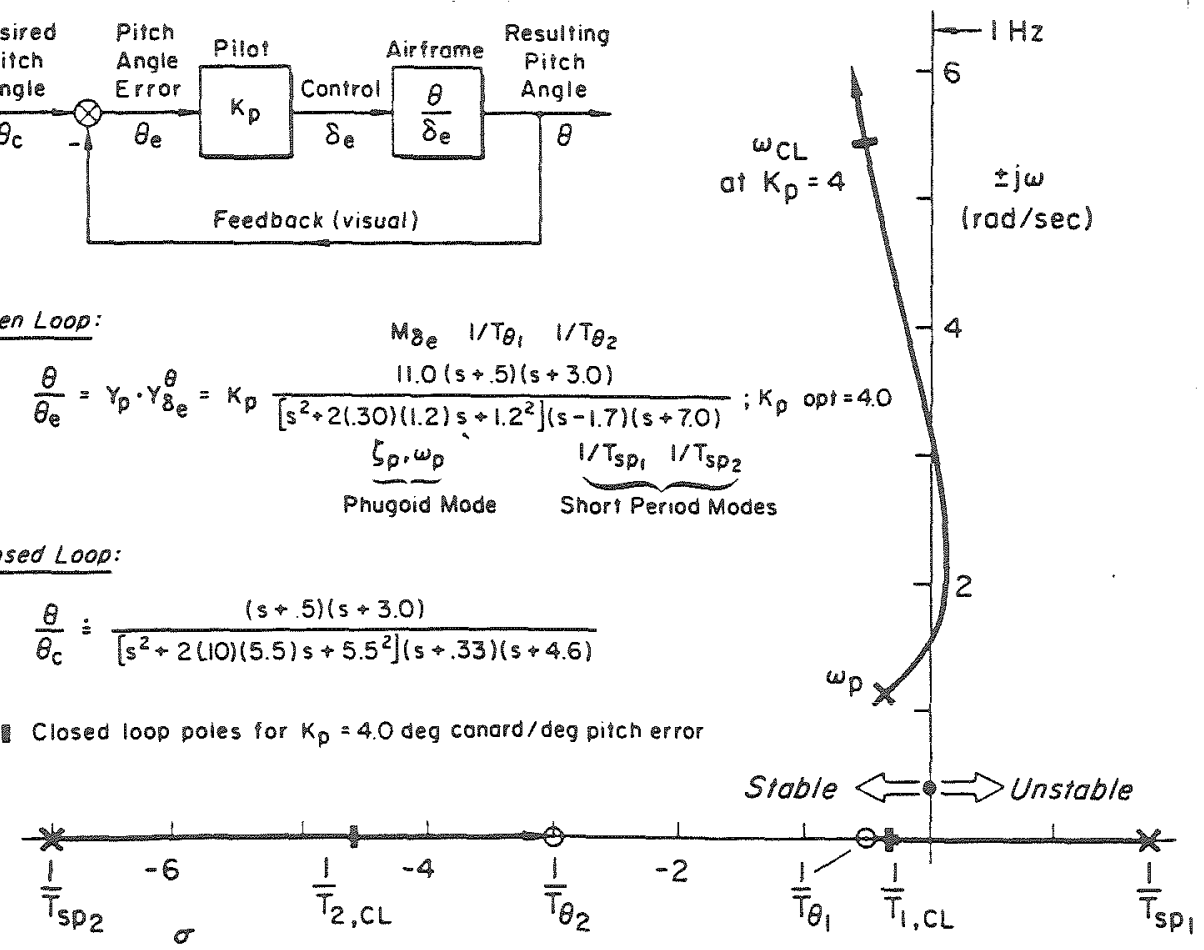

Figure 17. Root Locus Diagram for Pitching Motions; Proportional Control Law for Pilot Closure (Pitch Angle Error) 


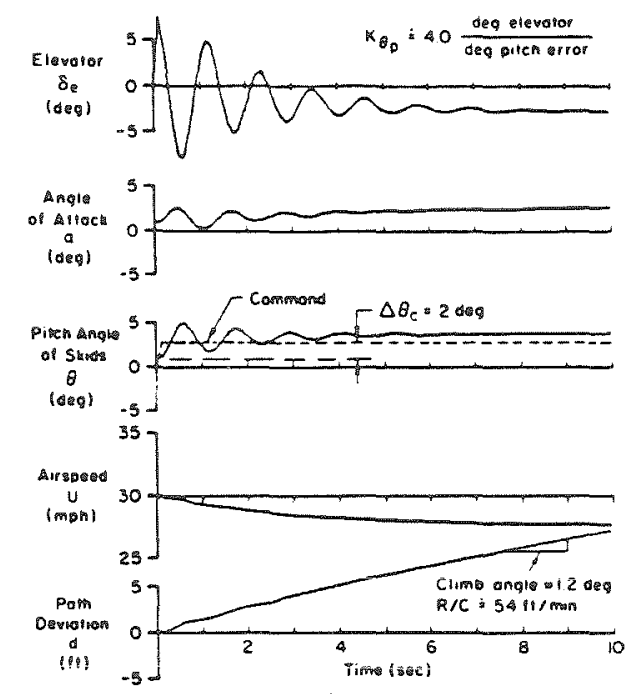

Figure 18. Closed Loop Time Response in Pitch
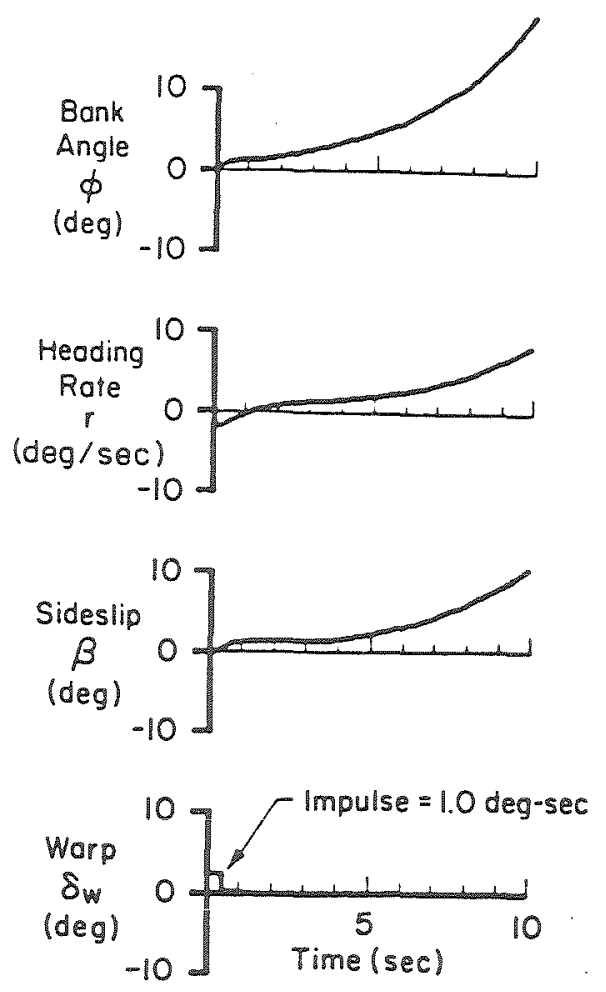

Figure 19. Open Loop Time Response in Roll and Sideslip

Open LOOD (worpo linhed rudder):

$$
\frac{\phi}{\phi_{e}}=k_{p}=\frac{5.8[47.1 .2]}{(-.3)(3.8)[.6 .1 .3]}
$$

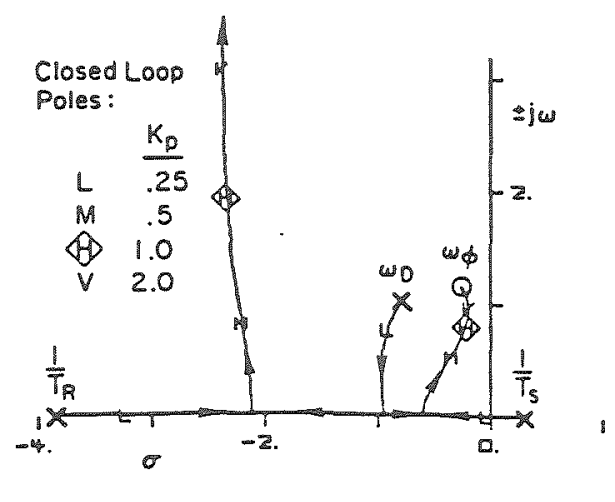

Q) Warp Alone

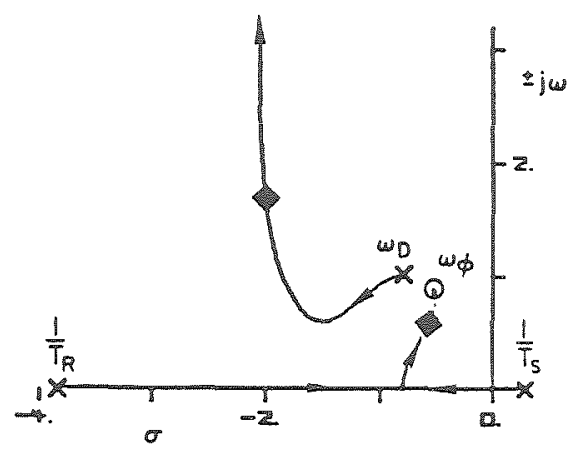

b) Linked Rudder $\left(\delta_{p}=-2.5 \delta_{t y}\right)$

Figure 20. Root Locus Diagram for Lateral 

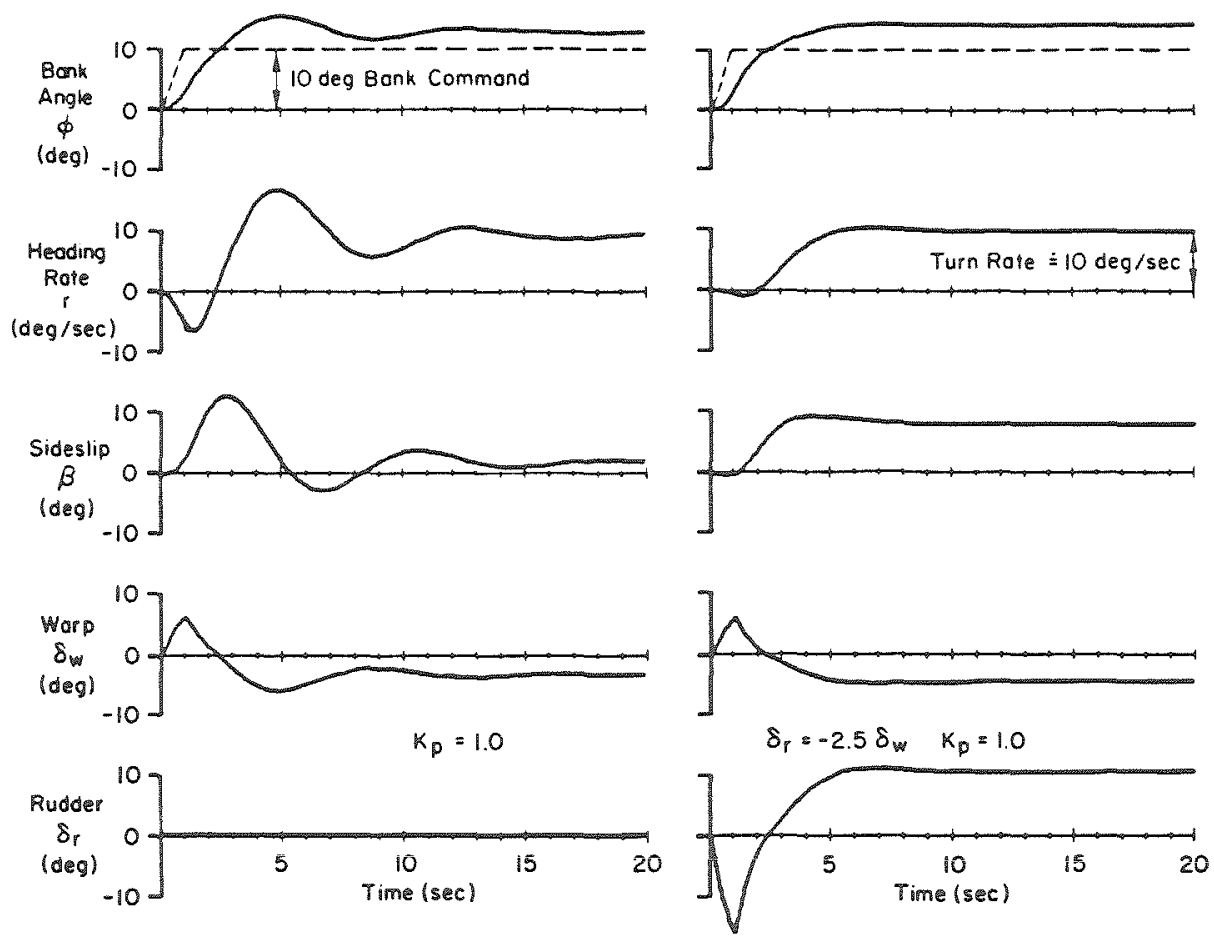

o) Worp Alone

D) Rudder Linked lo Woro

Figure 21. Closed Loop Time Response of Lateral Motions
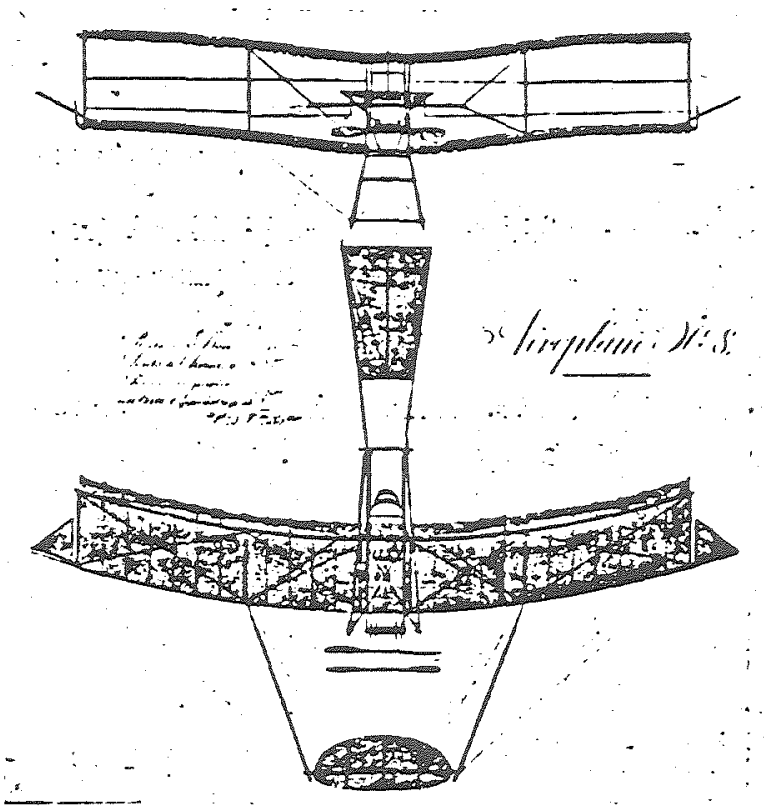

Figure 22. Ferber

Airplane 非9 (1909)
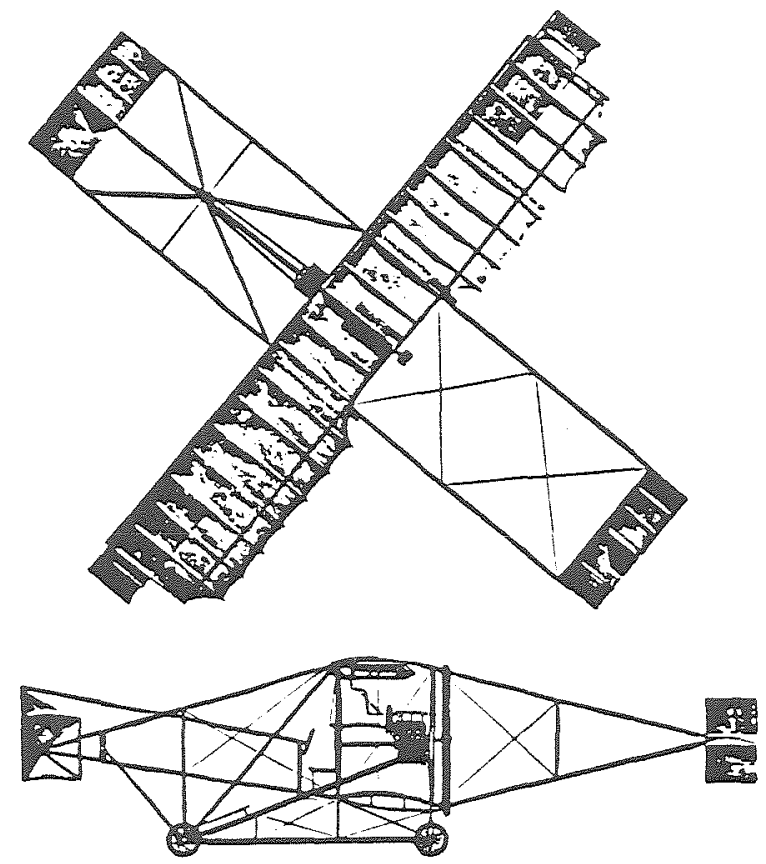

Figure 23. 1909 Curtiss "Golden Flyer" 

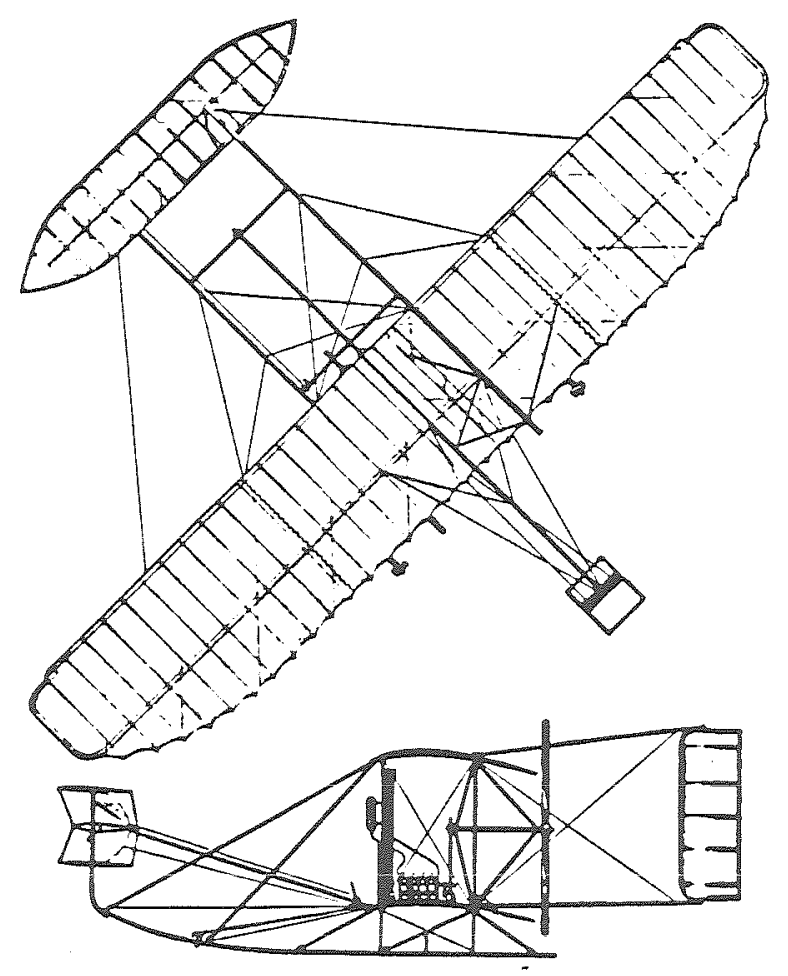

Ejgure 24. 1908-1909

Wright Airplane
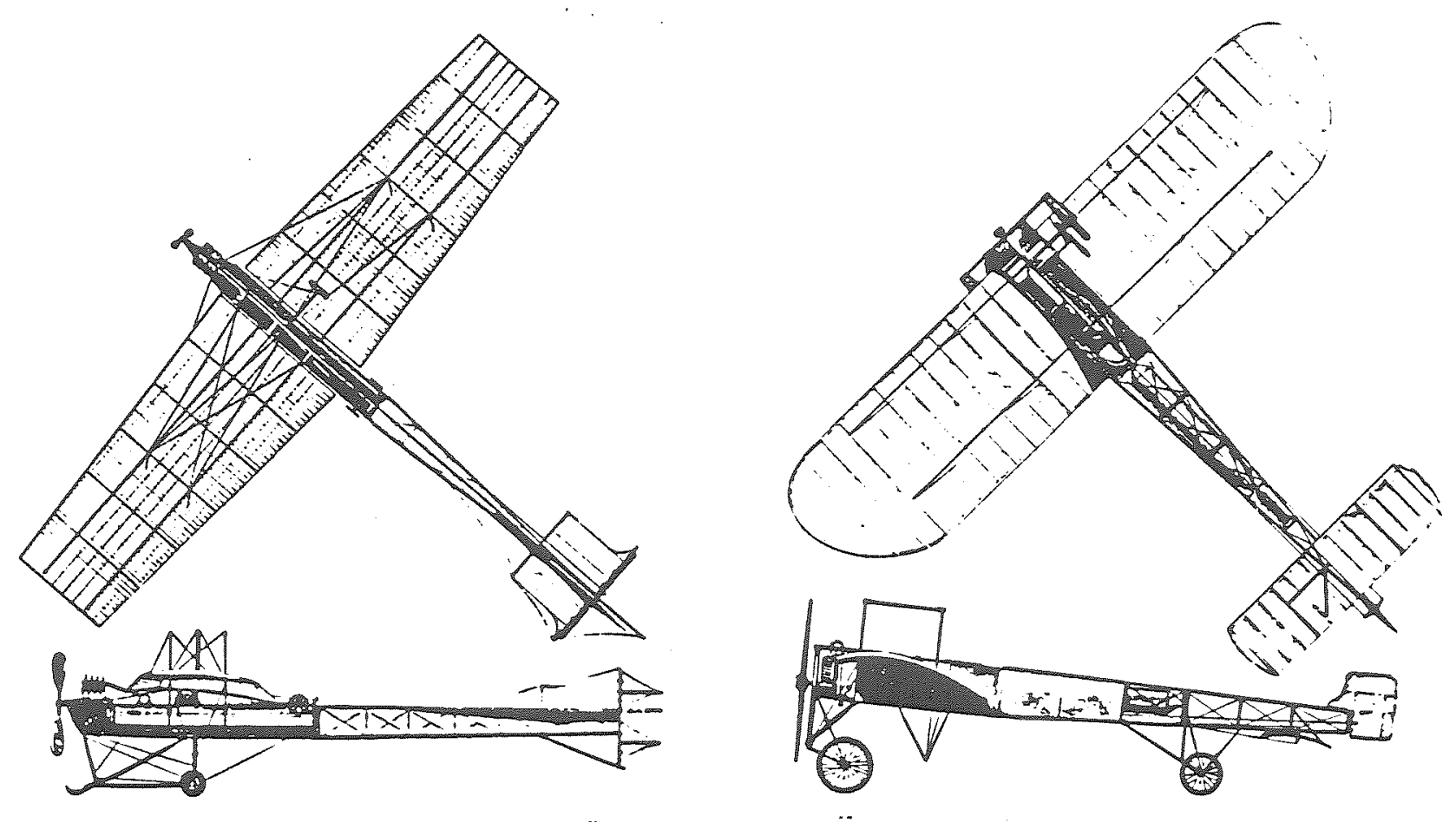

Figure 26. 1909 Antoinette VI 
standard procedure which in fact persisted for many years. An example of the calculations may be found in the article by Chanute appearing in the 1907 Pocket-Book of Aeronautics. ${ }^{21}$

Given that incomplete theoretical framework, the Wrights must have had trouble interpreting their results. Evidently they became satisfied with their approach and were obviously able to draw the conclusions they needed from their tests. Despite their careful planning and intentions to gain much flying time, the Wrights were able to fly their $1900 \mathrm{kite} /$ glider for only two minutes as a glider and of that only ten seconds were piloted, by Wilbur. Nevertheless they were satisfied that they were on the right track. They proved their techniques of longitudinal and lateral control, and confirmed their choice of a prone position for the pilot, to reduce drag. Tests were done with the horizontal surface either fore or aft of the wing. They finally settled on the canard configuration. They believed that they had more control, giving them better chances for avoiding the conditions encountered by Lilienthal and Pilcher who were killed flying their gliders with aft tails. It was also important that they could see what the surface was doing during flight, a significant help during their later tests.

The great disappointment of the tests in 1900 was that for a given angle of attack, the lift was less and the drag was greater than they had expected on the basis of Lilienthal's data. They concluded that, although inaccuracies in Lilienthal's results were possible, more likely their wing had too little camber for the data to apply.

So they returned to Kitty Hawk in 1901 with a larger glider (Figure 3 ) having section camber increased from 1:22 to 1:12 (approximately a parabolic camber line). The wingspan was now 22 feet, giving a 33 percent increase of wing area to 290 square feet. With a structure weighing 98 pounds and a 145 pound pilot, the wing loading was .78 pounds per square foot. It was the largest glider anyone had tried to fly. Although it looked like the $1900 \mathrm{kite} / \mathrm{glider}$, it became in many respects the most important research vehicle in the Wrights' program. In 1901, the Wrights divorced themselves entirely from the work of others and they uncovered, and solved, the remaining basic aerodynamic problems determining the configuration of their aircraft.

With Wilbur flying, the first flights in 1901 were nearly disastrous. They did not bother to test the machine first as a kite and Wilbur discovered immediately that he could not control its severely undulating motions. Twice during the first day's tests, the angle of attack became too large and the glider stalled. It was a fortunate consequence of the configuration that the canard stalled first; even though the pilot lost pitch control, the altitude was low, the wing continued to lift and the machine mushed slowly to the ground, striking in a nearly horizontal attitude. That was in striking contrast to Lilienthal's fatal crash: in that event, the wing stalled first, probably at an altitude of 20-40 feet. He had inadequate pitch control by moving his body fore-and-aft, and even with the aft tail still lifte ing, the craft struck the ground at considerable speed.

Wilbur's successful recoveries from the stalled condition he so feared convinced him of the merit of the canard configuration. From then until 1910 the Wrights had no interest in trying the aft tail. Still, at this point they were faced with the problem of determining the reason for the glider's erratic behavior preceding the stalls and crashes. With a clever series of tests flying the biplane as a kite the brothers found that 
as the angle of attack increased, the center of pressure moved forward (as expected) until at some value incidence the movement of the center of pressure unexpectedly reversed. When flying, Wilbur had not been prepared for that behavior and had evidently used the pitch control in such a fashion as to aggravate rather then reduce the undulating motions of the glider.

He then correctly concluded that the large camber caused the reversal of motion of the center of pressure. The brothers solved the problem by installing king posts and extra rigging to pull the middle sections of the ribs downward on both wings. The results were immediate and satisfying. Wilbur made some 30 glides after the modification, the longest one lasting 17.5 seconds and the greatest distance was 390 feet.

During the last week of testing Wilbur made a fundamental observation about the behavior of an aircraft when it is turned. He recorded in his diary that the "upturned wing seems to fall behind, but at first rises". On August 22 he wrote to Chanute: "The last week was without great results though we proved that our machine does not turn (i.e. circle) toward the lowest wing under all circumstances, a very unlooked for result and one which completely upsets our theories as to the causes which produce the turning to the right or left". Already in their first extensive light tests the Wrights had properly executed turns, by banking the airplane to provide the required component of lift directed to the center of the turn. Such a maneuver would have been possible with Lilienthal's hang-gliders but there is no indication that he, Pilcher or Chanute understood the principle. They had difficulty enough trying to make straight stable glides.

Wilbur's remarks show that he had found the phenomenon now called adverse yaw: in a turn, the aerodynamics of the wing generate a yaw force tending to rotate the craft in the direction opposite to the desired turn. It was because he was simultaneously theorist, inventor, builder, and test pilot that Wilbur was able in the course of three weeks' fying to make two crucial discoveries: the influence of camber on the position of the center of pressure; and adverse yaw.

The tests in 1901 again produced less lift than the brothers had predicted. They now were convinced that Lilienthal's data for curved airfoils was wrong. That prompted them to be gin their series of wind tunnel tests in the fall of 1901 . Theirs was not the first wind tunnel they had no doubt learned of previous work from their reading. But they were the first to obtain systematic airfoil data suitable for design. They used the wind tunnel as well to investigate the drag of struts and the influence of wing planform - they discovered that for constant area, a wing of higher aspect ratio has less drag.

It is well-known that the Wrights began their wind tunnel tests because they doubted Lilienthal's results. What is not widely recognized is that they soon discovered that Lilienthal's data were substantially correct. The following selections from Wilbur's diary ${ }^{5}$ is a superb illustration of the objective and thoroughly professional fashion in which they carried out their work:

October 6, 1901

I am now absolutely certain that Lilienthal's table is very seriously in error, but that the error is not so great as I had previously estimated ... If in our Kitty Hawk calculations we had used a coefficient of .0093 instead of .005 the apparent advantage of our surface over the plane as per the Duchemin 
formula would have been much greater. I see no good reason for using a greater coefficient than .0098.

October 16, 1901

It would appear that Lilienthal is very much nearer the truth then we have heretofore been disposed to think.

November 2, 1901

Lilienthal is a little obscure at times but, once understood, there is reason in nearly all he writes.

December 1, 1902

The Lilienthal table has risen very much in my estimation since we began our present series of experiments for determining lift ... for a surface as near as possible like that described in his book the table is probably as near correct as it is possible to make it with the methods he used.

The data are replotted in modern terms as Figure 4.

Thus the Wrights concluded that the cause of the high prediction of lift force was not due to errors in Lilienthal's data, but to a high value of a coefficient. In 1752 the preeminent English civil engineer of the eighteenth century, John Smeaton, had published data for the drag on a plate oriented perpendicular to a stream. (The data had actually been taken by a Mr. Rouse using a whirling arm but his contribution has rarely been cited.) From the data, the drag on a plate having area $S$ in a stream moving at speed $V$ $(\mathrm{MPH})$ is

$$
D=0.0049 V^{2} S
$$

The 0.0049 was called Smeaton's coefficient. That value persisted for 150 years and was accepted by Lilienthal who used it as a normalizing factor in reporting his data. As Wilbur noted in the first diary entry quoted above, he and Orville determined that its true value is 0.0033 which is indeed confirmed by the best data now available. They never actually measured the coefficient directly but inferred its value by clever use of the results of their wind tunnel tests on airfoils and a few measurements of the aerodynamic force on a full-scale wing.

The Wrights returned to Kill Devil Hills in August 1902 with a glider having about the same weight and area as the 1901 version, but built with a greater aspect ratio (Figure 5). They used a new airfoil section, the best they found from their wind tunnel tests and the one they used for the next nine years. The most obvious and important change of configuration was the addition of a double vertical tail; it was rigidly mounted and never intended for steering. Sometime after their 1901 fying season, the Wrights had figured out that they needed a vertical aft tail to compensate the adverse yaw moment generated in turns.

Initial tests showed that indeed they had a better aircraft. With the new wing they had a much-imporoved lift/drag ratio and the difficulties with longitudinal control were less. And the vertical tail did reduce the yawing tendency in a turn.

The tests also showed an excessive response to side gusts, lifting one wing and causing the other to strike the ground, a fairly common occurrence under the conditions the Wrights were flying. So they set the wings with negative dihedral. Further testing gave the pilot even more trouble with lateral control then the $1901 \mathrm{ma}$ chine had. When the glider was hit by a side gust it had an uncontrollable tendency to oscillate in yaw.

Even more serious trouble arose in several 
of the turns. Both brothers were now flying and both experienced the beginning of a spin in the direction of the turn. It was evidently due to the adverse yaw accompanying sudden warp reversal to adjust a steepening turn. It was Orville's idea to correct the behavior by replacing the double fixed vertical tail with a single moveable surface. Wilbur suggested that its operation should be tied to the warping wires. Thus the vertical tail could not be operated alone. Nevertheless, the coupled warp/tail control did significantly reduce the tendency to spin.

Those modification completed the configuration and the control system the brothers employed in their 1903 'Flyer'. Not until the end of 1904 did they disconnect the vertical tail and finally achieve independent control of pitch, roll and yaw.

By the end of their 1902 trials, both brothers knew how to fly. They had a configuration ready to modify for powered flight. Their idea now was to enlarge the design, install a propulsion system and produce the first man-carrying powered flight. After trying unsuccessfully to purchase a suitable engine from manufacturers, they decided to design and build their own. It was not a new task, for they had already built a gaso line engine to power machinery in their bicycle shop. By March 1903 they had what they considered an adequate engine: it developed 12 horsepower (perhaps 15-16 until it became too hot) and weighed about 180 pounds. Their engine was in fact quite inferior to engines built by Langley in the U.S. for his unsuccessful 1903 airplane, and later by Levavasseur in France: they weighed about 4 pounds per horsepower, less than onequarter of the Wrights' design.

After they had completed their engine, the brothers discovered, that, contrary to their as- sumption, they could find no basis for designing efficient propellers. The only useful result available from work on ship's propellers was that for a given power output, best efficiency is obtained if the diameter is as large as possible. That explains their choice of large propellers: 8.5 feet in diameter.

The Wrights were therefore forced to work out their own procedure. Unaware of Drzewiecki's earlier work, but well-prepared with their knowledge of airfoils, they developed their version of what later became known as bladeelement theory. Each segment of the blade is treated as a section of a wing; the lift and drag on the segment are calculated with proper account taken of the forward speed of the aircrait and the rotational speed of the propeller. The Wrights' analysis of propellers was a crucial mat ter, for without the efficiencies they obtained, they would not have been able to fly with the engine they had in 1903.

Thus the geometry of the 1903 'Flyer', Figure 6 , was essentially the same as that of the 1902 glider. It is a large airplane, having a span of 40 feet, 4 inches, chord 6 feet 5 inches and total wing area of 510 square feet. Total weight with pilot was 750 pounds, giving a wing loading of 1.5 pounds per square foot. That was a considerable increase over the wing loading of the Wrights' gliders, but the airplane still qualifies as an ultra- light by present standards!

The Wrights arrived at Kill Devil Hills on September 25, 1903. The 'Flyer' had not yet been assembled. When weather permitted, the brothers sharpened their flying skills with the 1902 glider. They spent the rest of their time preparing the 'Flyer' and carrying out preliminary checks that included static load tests and initial operation of the propulsion system. Var- 
ious development problems delayed their first flights until December 17.

\section{History and Present Status of the}

\section{AIAA Wright Flyer Project}

The project began when Howard Marx, as Chairman of the Committee on Special Events, L.A. Section, advertized in the Section Newsletter for volunteers to join the effort. I telephoned Howard and a few days later, he, Frank Baran and I met for dinner to discuss the possibilities. As a result of our conversation, I was designated first test pilot; in return for that privilege, I also agreed to act as Chief Engineer. Howard became the second test pilot. Frank moved out of the local area sometime later and is no longer associated with the project.

The advertisement generated a large number of volunteers, enough to build a substantial organization before we had a place for construction. By the end of 1979 we had roughly 50 people involved, assigned to the groups shown in the organization chart as it existed in 1980 (Figure 7). Owing to demanding administrative duties in the AIAA Section, Howard Marx resigned his position as Chairman to become Deputy Chairman, a position he still holds. Jack Cherne took his place as Chairman, and is also number four test pilot. The leadership of Cherne and Marx has been crucial in keeping the Project going through many ups and downs. It hasn't always been easy!

Our first problem was finding a work place. That took more than a year - it's difficult to find a large enough place more-or-less centrally located in Los Angeles and free of rent. At last in 1980 the Northrop Corporation generously provided an area in one of their storage buildings. Then over a year later we moved to our present location in another Northrop building. It's an area roughly 45 feet by twenty feet, enclosed by a locked chain link fence and now covered with sheet plastic to keep out dust (Figure 8). We are greatly indebted to Northrop for their continuing generosity and support.

While we searched for a work area, the project committee chairmen met regularly, every month or so for planning sessions. Separately, the committees met to carry on their work. The Aerodynamics Committee, headed by Chuck McPhail (Rockwell) and Henry Jex, analyzed the performance, stability and control of the Flyer. Don Crawford (TRW) and Mel Schorr (retired and since deceased) were major contributors. Dabney Howe and Henry Jex worked out the wind tunnel test programs. John Graves (Hughes Helicopter) headed the work on the propulsion system until his move to Arizona. We have purchased a Revmaster-modified VW engine, with a gearbox, for the flying aircraft.

For the past three years Carl Friend (retired from Lockheed) has been in charge of loads and structural analysis. He has done practically all of that work, including a complete stress analysis of the full-scale aircraft and detailed structural design changes as required for increased strength. That has been a major chore since we must show that the aircraft will withstand 3g's to qualify for wind tunnel tests. Carl is also our expert in rigging the airplane, a task that he accomplished almost alone. Another requirement for the tests is that an electric motor must be used to drive the propellers; most of the necessary design work was done by Chuck McPhail and Jack Cherne. Wallace Perry has built a stand to test the propulsion system prior to installation in the aircraft.

Of course the real manual labor has gone to construction. Fred Erb (Northrop, now retired) 
has been in charge of this part of the project from the beginning. In addition to planning, he has done much detailed design, both of structure and jigs, and has done a great part of the construction himself. Fred's deputy until his death in November 1983 was Harlan A. "Bud" Gurney. Bud and Charles Lindbergh were student pilots together in 1923. Later Bud parachuted from Lindbergh's plane during their barnstorming days. The two -emained lifelong close friends. Having retired as a United Airlines Captain in 1968, Bud lived in a suburb of Los Angeles and joined the AIAA Wright Flyer Project in 1979. In addition to his endless supply of flying stories, his experience, help and enthusiasm were invaluable. He taught us much about construction techniques and did a large part of the early construction himself, with help from Koon Wah Lim (retired from Douglas). We now miss also the valuable services of Henry Rezler, who suffered a fatal heart attack in 1983. Henry did much of our early detailed design and was our resident draftsman as well. More recently, Chuck Thomas (Lockheed, retired) has contributed a great deal of time and effort to both aircraft and facility construction.

A project like this requires a certain amount of administrative work - in fact a lot. Helping Jack Cherne in this respect, Bud Chamberlain ( $A F$, retired and now in private business) has been our chief administrator, a job which has included keeping accurate minutes of our many meetings. He is also number five pilot and has been one of the most active participants in construction work. Our treasury has been tended from the beginning by Evan Huie (Northrop) with a fine tightfisted touch. Somewhat less than half of our beginning sum of $\$ 20,000$ remains, an amount which may be almost enough to complete our plan for building the two aircraft. Gene
Coates (Rockwell) has helped our cash flow by running various promotional activities.

To help us gain a better understanding of the effects of configurational changes, Bob Martz (TRW) has constructed a $1 / 8$ scale radio controlled model, with help from Wendell Seward. The model is electrically powered. To date it has completed taxi tests, several short "hops" with a training tail, and one major crash without the training tail.

We also have an Advisory Board, chaired by Roger Schaufele (V.P. Engineering, Douglas Aircraft Company). It is composed of several people from local industry including Bob Clark (Northrop Corporate Offices) and one (Paul Lord) from California Polytechnic. One board member, Bill Sparks (Westinghouse, retired) is number three test pilot and has been among our most active participants in the project, as well as egging us on if he detects flagging efforts. Bill was a major contributor to the construction and rigging of the wings. His value has been enhanced by his height, many times a great help, especially during assembly of the complete aircraft.

We assembled the uncovered structure nearly three years ago (Figure 8), complete except for the instrumentation, control actuators, power unit and support attachments required for the wind tunnel tests. Completion of the aircraft has been delayed for various reasons, but even in its present form the aircraft has served well. Twice we have moved it for public display, first for an event at the Northrop Aircraft Division in Hawthorne, and later for an anniversary celebration at the Los Angeles Museum of Natural History. Moving the complete aircraft is a difficult job (Sparks was effectively transportation manager and made things work) but the results were worth the effort. After all, it's not often that avi- 
ation enthusiasts can view a full-scale uncovered Wright 'Flyer'!

During this project, there have been times when progress sputtered, or halted. The beginning period was slow because of our difficulty finding a work facility. Since then, key people seem periodically to get tied up with other work, or travel, or for some other reason cannot do on time what they had promised. So we all have had to exercise tolerance and patience at some time or other. It's hard to do things by Committee!

Nevertheless, we do have the full-scale aircraft for wind-tunnel tests now being covered seven years after we started construction. None of us had much covering experience but we seem now to have solved all problems, ofiten by trial and error. Owing to internal structural changes from the original design, to gain strength, we cannot follow the Wrights' covering methods exactly. However, the main problem is simply the routine chore of sewing, sewing, sewing by hand and machine. Dara Chang, a recent graduate of Caltech, has done almost all the machine work; the heaviest work has been generously donated by Philip Draperies, Pasadena, CA. In addition to most of those listed above, father and son Bill and Bob Haynes have been loyal seamsters. We expect to have the covering completed late this winter. When the aircraft is once again assembled, it will undergo static load tests in preparation for the wind-tunnel program.

\section{Aerodynamics, Stability, and Control of the 1903 Flyer}

From the beginning of the Wright Flyer Project, it has been our intention to interpret the Wrights' accomplishments in terms of the knowl-

* This section is a summary of material in references 2 and 3 . edge gained in the eight decades since their fights in 1903-1905. Henry Jex, who has been responsible for almost all of the detailed analysis discussed here, has referred to this program as our "numerical archeology". Owing to the inclinations of the authors, we have been concerned primarily with matters of aerodynamics and flight mechanics. Although one recent paper ${ }^{24}$ has provided some interesting observations about the structural design of the 1903 'Flyer', much remains to be done on that subject.

Our analysis of the flight control dynamics of the 1903 'Flyer' is based on results obtained from the wind tunnel tests of two models, a $1 / 6$ scale model tested at the California Institute of Technology, and a $1 / 8$ scale model tested in a private wind tunnel whose owners may identify themselves at a later date. The data have been analyzed, partly with the help of some computational aerodynamics calculations performed at the Douglas Aircraft Company, to provide firm assessments of the stability and control derivatives of the 1903 'Flyer'. Using classical aircraft dynamic stability and control theory, and pilot vehicle closed-loop control methodology, analyses were carried out at Systems Technology, Inc. to help us understand how the aircraft likely behaved when the Wright Brothers flew it. The results shed new light on the controversy surrounding the interconnected wing warp/rudder invented by the Wrights for satisfactory lateral and directional control on their intentional use of wing anhedral, and on their general emphasis on good controlover good stability.

Nothing related to the Wright Brothers has created more confusion, controversy, discussion and at rimes vitriolic argument than questions of equilibrium, stability and control. There is fairly general agreement that the Wrights' expe- 
rience with bicycles taught them the virtues of good control. A bicycle is unstable without active control by the rider. Thus the Wrights were not deterred by the possibility of flying an unstable vehicle which could with practice be successfully operated, providing the means existed for easy control. It is also clear that control was always a central issue during development of their aircraft.

What is by no means evident is the extent to which the Wrights inadvertently produced unstable aircraft in their pursuit of a controllable one. They certainly refused to follow their contemporaries who were preoccupied with the goal of inventing an intrinsically or automatically stable airplane. Their choice of the canard configuration, the most distinctive feature of the Wright aircraft, was not based on sound technical grounds of aircraft stability. It was rather a matter of control in pitch, especially under extreme conditions. In fact, the Wrights did not understand vehicle stability in the static and $d y$ namic sense that we do now. The reason is fundamental: seldom in their work did they consider explicitly the balance of static or dynamic moments.* They shared that ignorance with all others trying to build aircraft at that time. So strictly, whether their aircraft were stable or unstable was an accidental matter. Often, changes in a design were made which would change the

* We must hedge a bit. The right wing of the 1903 'Flyer' was about four inches longer than the left, to compensate the weight of the engine, which was mounted to the right of the pilot. This is clear evidence of careful design, and an indication that the Wrights understood some of the need to balance mo ments as well as forces. They also used counterrotating propellers to balance out the propulsive torques. stability, and not always favorably. But the motivation was always the desire to affect some controllable characteristic, such as undulations in pitch. From this point of view, the question of the Wrights' intentions to design an unstable airplane is meaningless.

Four cases are possible for a wing/tail configuration: the smaller surface is either forward or aft of the wing, and each of those configurations is either stable or unstable. The four are shown in Figure 9, with labels citing examples of each location of the neutral points (position of the center of gravity for neutral pitch stability) are labeled N.P. The lengths of the arrows in Figure 9 represent the relative loads per unit area or lift coefficient, $C_{L}$, when the configuration is trimmed for equilibrium in pitch. This shows the most important distinction between stable Figure $9(a)$ and unstable Figure $9(b)$ configurations: whatever the relative sizes of the surfaces, the forward surface carries more load per unit area when the configuration is stable: the value of its lift coefficient is greater than that of the aft surface. As a result, if the angle of attack of a statically stable aircraft is increased, the forward surface will usually stall first. This means that for a conventional stable aircraft with aft tail Figure 9(a)-1, the wing stalls first and may lose lift suddenly. However, the aft tail continues to be effective and can be used to generate a strong nose-down moment, causing the wing to recover its lift. When the forward surface of a stable canard stalls Figure $9(\mathrm{a})-2$, the nose drops, keeping the main wing unstalled. But while the canard elevator is stalled, pitch control is lost and the stall is aggravated by the canard downward velocity.

A statically unstable aircraft having an aft tail Figure 9(b)-2, can be extremely difficult for 
a person to fly, although birds often fly in this condition (e.g. gliding pigeons and eagles). The most critical condition again arises with the behavior at high angle of attack. Here, the aft tail may stall before the wing, control is lost and the wing stalls soon after. The possibility of operating such "relaxed stability" configurations successfully (thereby gaining their advantage of increased efficiency) with the use of automatic controls is a subject of growing interest and application in modern aircraft design.

And so we arrive at the final case, Figure $9(\mathrm{~b})-4$, the unstable canard used by the Wright Brothers (and rarely since until the current Grumman X-29). If the angle of attack is sufficiently high, the aft surface, now the main lifting surface, may stall first. While this appears to be serious, the saving grace is that, unlike the previous case, control is not lost. That is probably why the Wrights were successful with their early unstable gliders which had airfoils with small aft camber - they always had control. If the wing has large camber, as with the Wrights' 1903 airfoil, the canard must carry additional lift to balance the large diving pitching moment due to the wing. Further, a canard surface within a few wing chords of the wing experiences a large upwash angle of attack due to the wing's circulation effects. As a result, the canard elevator may still stall first as the angle of attack of the aircraft is increased; that seems to have been the case for the 1903 and 1904 Flyers.

The 1903 'Flyer' was not merely a "relaxedstability" configuration, for which the negative static stability margin (distance from C.G. to $N P$, in chords) is seldom allowed to go beyond -.05 to -.10 chords. As our wind tunnel data show, its neutral point was at about .10 chord while the C.G. was at .30 chord giving a negar tive static margin of -.20 , and an aircraft severely unstable in pitch. Based on their diaries as discussed elsewhere, ${ }^{2}$ we feel that the Wrights simply did not understand these aspects of static trim and stability. They were somewhat lucky in their early fights, because their statically unstable canard aircraft could usually be controlled out of the very wing stall they were hoping to avoid, but often encountered.

Two members of the Wright Flyer Project, have used modern computational techniques to calculate some of the major aerodynamic characteristics of the aircraft. Using two different vortex lattice computer programs, James Howford and Stephen Dwyer of the Douglas Aircrait Company have calculated load distributions, lift and pitching moment for the Flyer, for various linear and rotary motions. ${ }^{22,23}$ We believe that these are the first such analyses of this aircraft and, in fact, may be the first applications of vortex lattice theory to a biplane. Figure 10 shows how the airplane is treated for this purpose. The wings, canard and vertical tail are approximated as flat surfaces having zero thickness, and having no volume-displacing fuselage, not a bad assumption for the 1903 'Flyer'. For these calculations the surfaces have been divided into three hundred panels, and no account is taken of the struts, truss wires and other structure external to the load-carrying surfaces. Propeller influences were also not included. In the vortex lattice method the flow is assumed to be inviscid so the friction drag is zero. The drag due to lift (the induced drag) can be calculated but is not included here, because their program was set up for loads normal to the wing chord plane (leading edge suction effects are also omitted).

Examples of Howford's load distributions are given in Figure 11. The loading per foot of 
span on the lower wing is plotted to an arbitrary (but consistent) scale for several conditions. Figures $11(\mathrm{a})-(\mathrm{c})$ show the influence of canard deflection. In part (a) the load distribution has the nearly elliptical form expected for changes of incidence for the wing alone. Deflection of the canard (nose up) produces downwash behind the canard and upwash in the region outside its tips. This produces a negative loading in the central portion of the wing, and a slight increase in the outboarc regions, as shown in Figure 11(b). The net loadin - on the wing for changes of both canard anc ..ng angle of attack is shown in Figure 11(c). The downwash effects overpower the upwash effects, giving a net loss of wing lift for the canard configuration compared to the wing alone.

In Figures $11(d)$ and $11(e)$, the incremental normal loadings on the wing due to pitch and yaw rates are illustrated. The wake of the canard has a large influence in pitch, and relatively less in roll.

Not shown here, but evident in the results of the vortex lattice calculations for the complete aircraft, is the significant upstream influence of the wing. A strong upwash field is generated, decaying within several wing chord lengths ahead of the wing. Because the canard is located within the upwash field, this magnifies the contribution of the canard to pitch instability by an additional 25 to 30 percent.

These results show directly the obvious fact that the flow induced by the canard may have substantial effects on the lift generated by the wing and vice versa. This must be included in analysis of the aerodynamics of the 'Flyer'. Suitable integration of results such as these will give the total lift and moment for the aircraft. The good accuracy of the calculations will become ap parent upon comparison with data taken in wind tunnel tests.

The $1 / 6$ scale wind tunnel model (Figure 12) was built of wood and fabric with steel truss wires, a structure very similar to that of the original 'Flyer'. Tests were run for the most part at $1 / 6$ full-scale Reynolds number or less, a wind speed of $30 \mathrm{MPH}$. A few were run at $60 \mathrm{MPH}$. As a result, the fragile structure suffered considerable internal damage and unwanted distortions of the wing surfaces. Some of the results seems to be biased because of that damage.

Extensive tests were taken with the $1 / 8$ scale model (Figure 13) made of stainless steel. Reynolds numbers ranged from 50 to 90 percent of the value in full-scale fight. Data were taken with changes of configuration to investigate passible modifications for the full-scale flying reproduction.

Figure 14 shows results for the lift curve and drag polar. Because the steel model had larger structural members, its minimum drag coefficent is higher than that for the $1 / 6$ scale model. The agreement of the drag at the cruise lift coefficient must be regarded as fortuitous: data for drag are subject to many tunnel corrections and especially for these models the results may be sensitive to the value of the Reynolds number. A detailed drag break-down for the 1903 'Flyer' was carried out by Chuck McPhail. It's a very tedious calculation (look at all the parts exposed to the wind!) and gave a minimum drag coefficient of 0.0856 , remarkably close to the value measured for the $1 / 6$ scale model.

The lift-curve slope is a more robust quantity. According to the data taken with the steel model, the slope is very closely matched by the calculations based on vortex lattice theory, showing a skid angle of attack of about one degree at 
cruise (allowing for the approximately 4.3 degree wing-to-skid incidence). This suggests again the understanding of aerodynamics possessed by the Wright Brothers: it appears that the incidence setting of the wing, with respect to the skid rail, was very closely that required for cruise flight. The lift curve for the covered model has closely the same slope as the other two results but is displaced by roughly four degrees to higher angles of attack. This may be due to an average reduction of the aft camber of the airfoil due to distortion of the rib structure. In any case, both sets of data show that the cruise lift coefficient is well below the value for stall of the aircraft, further evidence of proper design by the Wrights.

A summary of our present understanding of the pitching moments of the 1903 'Flyer' is given in Figure 15.* The best data, those taken with the steel model, are displayed as open symbols; results are shown for three canard settings, 0 degrees and \pm 10 degrees. It appears that a deflection of about +6 degrees (nose up) is required for trim condition having zero pitching moment at the cruise lift coefficient of 0.62 . But according to Figure 8 , this is a statically unstable condition, with the steel model and theory in near perfect agreement that the neutral point is at about 10 percent chord for the 1903 'Flyer'.

The data taken with the $1 / 6$ scale covered model are plotted as the crosses. These show a smaller value of pitch down pitching moment at

* We have defined the reference location of the 1903 'Nlyer' center of gravity to be $30 \%$ chord aft of the leading edge of the lower wing and $30 \%$ of chord above the lower wing. Based on estimates by Pro fessor Fred Hooven of Dartmouth College (Emeritus, now deceased) and by Chuck McPhail of the AIAA Wright Flyer Project. The bottom of the skid rail is the horizontal reference. zero lift. Correspondingly, the elevator deflection for trim is nose down, producing a pitch-down moment on the airplane. The smaller pitching moment at zero lift is consistent with the smaller angle of incidence for zero lift shown by the data in Figure 14. Both deficiencies may be explained by somewhat less aft camber or a small amount of symmetrical twist (aft-portion of trailing edge up) of the wings on the covered model.

The strongly unstable pitching characteristic of the 1903 'Flyer' is arguably its worst feature, although as we shall see, the lateral characteristics are also poor. The large negative static margin (-20\%) and limited control trim range meant that the airplane was barely controllable. Three factors made the first flights possible: the low speed, high damping of the pitching motions, and, most importantly, the Wrights' fying skills obtained during dozens of earlier glider flights in 1901 and 1902. During their development work leading to the 1905 airplane, the first practical airplane, the Brothers made two important changes: they increased the area of the canard, and they added weight, as much as 70 pounds or more to the forward canard post, in the form of iron bars attached to the canard support posts, to bring the center of gravity forward.

So the Wrights, having validated Lilienthal's data, followed his lead and used thin, highly aftcambered airfoils resembling the cross-sections of birds' wings. They were misled to believe that only airfoils of that sort produced the highest ratio of lift/drag. This conclusion is valid if data are taken for small wings at the low speeds the Wrights used in their wind tunnel tests (i.e. at low Reynolds numbers, well below 100,000). Thicker airfoils having less camber are superior for full scale aircraft. However, it was the canard configuration combined with large negar 
tive pitching moment of the Wrights' airfoil that was their main problem; the small canard simply could not carry the needed trim loads at stable C.G. locations. Just by reducing the aft camber (or in fact keeping their late - 1901 de-cambered airfoil) they could have achieved enormous improvement in the longitudinal flying characteristics of their 1903 aircraft. In their later aircraft they apparently reduced the camber, but not as much as ay should have for good flying qualities.

One of the distinctive features of the 1903 'Flyer' is that the wings are rigged for anhedral - the tips are "arched", as the Wrights called it, about eleven inches below the centerline. They incorporated that feature, for reasons given early, as a result of their experiences in their gliding tests.

Although we are concerned in this project mainly with the 1903 'Flyer', it is interesting to learn what the Wrights did about anhedral in their later aircraft. In September 1904 they began practicing turns, attempting a full circle first on September 15. They succeeded on September 20. Then on September 26, Wilbur noted in his diary that Orville had been "unable to stop turning". The same entry appears on October 15, but this time the aircraft suffered serious damage. "Unable to stop turning and broke engine and skids and both screws, Chanute present." On the same day, Chanute noted in a memorandum, "Wright thinks machine arched too much and speed too great across the wind". (sideslip). Thus they seem to have correctly located the problem as the anhedral causing the spiral mode to be so unstable as to make controlled turning extremely difficult. Photographs of the airplane with anhedral (August 13) and without tip anhedral (November 10) are reproduced as Plates 84 and 86 , respectively, in reference 1.

The difficulties the Wrights encountered in turns were only partly due to the spiral instability. In all of the flights referred to above, the wing warping and rudder deflection were interconnected as in the 1903 'Flyer'. They recognized that this restricted the control they had in turns and, finally, in 1905 decided to operate the controls independently. The removal of all anhedral late in 1905, together with independent control of yaw and roll, gave the Wrights an airplane they could turn easily at speed and altitude.

The most fundamental aspect of the Wrights' invention of the airplane was the idea of the need for simultaneous control of both roll and yaw motions. It is the foundation of their basic patent submitted in 1902 and granted in 1906. Wilbur had discovered the problem of adverse yaw in 1901. Warp and rudder deflections were interconnected in the 1902 glider and in the 1903 airplane. Although the controls were later made independent, interconnection was a fortunate choice for the 1903 machine, as we shall see below.

Our wind tunnel tests have greatly increased our understanding of the aerodynamic characteristics of the 1903 ' $F$ lyer'. It appears that the data are reasonable and agree well with predictions based on modern aerodynamic theory.

According to our data, the trimmed flight condition of the aircraft is near the optimum, being at a value of lift coefficent slightly less than that for maximum lift/drag ratio. This provided ample margin below stall of the aircraft, a primary consideration of the Wrights in view of Lilienthal's fatal crash. The flight speed of 30 $32 \mathrm{MPH}$ was about 1.3 times the stall speed of about $22.5 \mathrm{MPH}$ based on the $C_{L} \max$ of the 
steel model near full scale Reynolds number.

The canard gave sufficient power in pitch to control the unstable motions, and the vertical tail was adequate to control yaw. The combination of wing warp for roll control and a linked rudder to remove the associated adverse yaw provided powerful lateral control for banking the airplane and for coping with gusts.

No contemporary aircraft had control of so phistication even approximating that of the 1903 'Flyer' until after the Wrights publicly flew their completed design in 1908.

With the wind tunnel data we have been able to clarify most of the important static aero dynamics of the 1903 'Flyer' - static stability and control effectivenss. ${ }^{(2,3)}$ By adding estimates of a few rotary derivatives, we can describe quite accurately the dynamic response of the airplane, in quantitative terms not available to the Wrights.

Because the 1903 'Flyer' logged a total fight time of only 1 minute 58 seconds, the flight characteristics and handling qualities of the airplane wre never fully tested. That it was flyable was of course demonstrated - under severely gusty conditions. By examining the two elementary transient motions of pitch and turn control, we can gain some idea of how the airplane probably behaved.

We assume that the airplane has a plane of symmetry containing the longitudinal and vertical axes. ${ }^{*}$ It is then a general theoretical consequence of the equations of motion that, if the

* The original 'Flyer' was built with the starboard wing approximately four inches longer than the port. This asymmetry was built in to compensate for the weight of the engine, which was mounted starboard of the centerline and which was heavier than the pilot who lay slightly to the left of center. Our disturbances away from steady flight are not too large, then the unsteady motions can be split into two parts: 1) purely longitudinal motions involving changes of the forward speed, pitch attitude, and angle of attack, and 2) the lateral motions comprising roll, yaw and sideslip. The dynamics of these two motions are not coupled and can be separately computed and analyzed even though both may be present as in a turn entry.

Because the 'Flyer' is a lightly loaded aircraft, contributions from apparent mass effects are significant. The most important, accounted for in the analysis reported here, are associated with heaving, pitching, and rolling accelerations. They cause the effective moments of inertia in heaving, pitching and rolling to be 1.28, 1.07 and 1.6 times the physical values and thus cannot be ignored. Such influences have always been important for neutrally buoyant airships and are also substantial for ultralight aircraft, of which the Gossamer human-powered aircraft the Wright 'Flyer' are all examples.

We have already established that the Wright Flyer was statically unstable in pitch. That means that if it is even slightly disturbed from a condition of steady flight, there is no tendency to restore the initial steady motion. Thus if the pilot does nothing, the airplane will exhibit a divergent nose-up or nose-down departure following any disturbance.

Figure 16 shows the computed results for a 0.1 degree-second pulse of the canard. This pulse input is represented in Figure 16(a). The remaining four parts of the figure clearly show the subsequent divergent motions in angle of attack, pitch (nose-up), airspeed (decreasing) and altitude (in-

assumption of perfect symmetry is only slightly strained by that detail and has small effects on our results. 
creasing). In approximately one-half second the amplitude of each motion doubles.

The airplane alone is obviously very unstable both statically and dynamically. However, it can be controlled by a skilled pilot - the practical consequence is that the combination of airplane plus pilot is a dynamically stable system. It is analogous to the manner in which a statically unstable bicycle with a trained rider is stabilized. So far as the pilot's reaction time is concerned, stabilizing the 1903 'Flyer' is roughly equivalent to balancing a yardstick vertically on one's finger. Practice is required - the Wrights had lots of that.

To analyze such "closed-loop" pilot control we assume that, in response to a disturbance the pilot tries to maintain level fight using a simple control law. The pilot can see the horizon and he knows where some horizontal reference line on the canard should lie with respect to the horizon in level flight. Then to restore level flight, the pilot deflects the canard by an amount which is proportional to the error between the actual location of the reference line and its desired position in level flight. Thus, the canard deflection is pro portional to the pitch angle error; the constant of proportionality is called the pilot's "gain". For simplicity we assume the pilot has used pure gain and has no delay.

The airplane and pilot, with the assumed proportional feedback law, constitute a closedloop feedback system. Using conventional methods, ${ }^{25}$ its dynamical behavior is shown by the root locus diagram given in Figure 17.

In the context of aircraft dynamics, the 1903 'Flyer' is distinctly not conventional. Because the airplane is statically unstable in pitch, the usual short period oscillation doesn't exist. It degenerates to two simpler fundamental motions, one of which decays with time and the other of which diverges following a disturbance with a time constant of only 0.6 seconds. The latter is responsible for the behavior shown in Figure 16. The "phugoid" mode is lightly damped, as is normally true, but it has a period of about five seconds. However, due to the static instability what we call here the "phugoid" is really something between the conventional phugoid and short period ascillation, sometimes called a "third mode" of longitudinal dynamics. ${ }^{26}$

Now suppose the pilot acts as described earlier, and continually deflects the canard in opposition to the perceived pitch deviation with pro portional gain $K_{p}$ to maintain a desired pitch attitude - the "loop is closed". As $K_{\mathrm{p}}$ is changed, each root traces a locus starting at the open loop cross, and hence the name "root locus diagram".

The filled squares in Figure 17 represent the roots when $K_{p}=4$, meaning that the pilot deflects the canard by 4 degrees for every degree of error he sees. Both roots on the horizontal axis now represent stable motions which always decay. The root representing the oscillation has now moved to higher frequency and is still lightly damped. This frequency, roughly $0.9 \mathrm{Hertz}$ (the period being about 1.1 seconds) is in the range for which a pilot-induced oscillations will occur. ${ }^{27}$ Pilot induced oscillations were likely a problem for the 1903 and 1904 Flyers, as shown by pho tographs in which the canard is deflected fully up or down, and were present even in some movies of the 1905 and early 1908 Wright aircraft.

Figure 18 is a sketch of the time response for a two degree climb angle command, but now the pilot exercises proportional error control $K_{p}=4$. In accord with the closed loop stability evidenced on the next locus plot, both the horizontal speed and the rate of climb reach stable asymptotic val- 
ues. The nose bobs up and down at about 1.1 cycles per second; after about two cycles the amplitude is reduced by half. Thus we have found that even though the airplane alone is seriously unstable in pitch, it is controllable by a reasonably skilled pilot.

Correlations of the 1903 'Flyer' longitudinal dynamics has been made with various procedures for rating handling qualities rating. Allowing for concurrently poor lateral control dynamics and the minimal mission complexity (maintain an airborne path for about one minute), the unstable 1903 'Flyer' would probably merit a Flying Qualities rating of 9.0 on the Cooper-Harper Scale: "Nearly impossible to fly".

The longitudinal behavior just described is quite consistent with previous expectations; what we have been able to provide are firm quantitative results. Lateral dynamics is a different matter: practically no attention has previously been paid to the problem of turning the 'Flyer', so our results are new. The Wright Brothers were the first to understand the correct method for turning an airplane. Lilienthal and other glider pilots he inspired were largely content to maintain lateral equilibrium by building wings with dihedral, and shifting their weight as required during fight. Contemporary experimenters with early powered aircraft, such as Farman in France, tried to skid around turns by deflecting the rudder. The Wrights realized that precise control of roll angle is essential for good turn entries and exits. They devoted a large part of their flight test program to the problem of turning; only af ter they were satisfied with their solution in 1905 did they set out to sell their invention. We have discussed the main features of their system for control of roll and yaw of the 1903 'Flyer'. Now let us see how it actually performed in flight.
Figure 19 shows the lateral response of the 1903 'Flyer' for an impulsive warp deflection of one degree-second (e.g. two degrees of warp held for one-half second) with no rudder deflection. The unstable nature of the motion is clearly shown by the rapid divergence of roll and sideslip angles. Note that owing to adverse yaw, the heading rate starts initially towards the direction opposite to that desired.

Evidently, to execute a turn with a fixed bank angle, the roll moment must first be turned on and then removed. Simultaneously, the rudder must be used in such a fashion as to compensate adverse yaw and reduce the sideslip to zero. Closed-loop pilot control is required to perform smooth turns.

Analysis of the closed-loop roll-control loop was carried out using the methods described above. We require that, beginning from steady level fight, the pilot actuate the controls in such a manner as to roll the airplane into a constant angle of bank. The root locus diagram in Figure 20 has been constructed for this situation. Below the block diagram is the equation labeled open loop response, giving the transfer function for the response of roll angle to wing warp, $\delta_{w}$. The crosses in the diagram again represent the open-loop roots of the denominator. One lies to the right of the vertical axis, and corresponds to the unstable "spiral mode". If the wings are impulsively warped, and returned to their undistorted state, or if the airplane is exposed to a short vertical gust unsymmetrical about the centerline, an unstable spiral motion will develop.

Another root lies far to the left: this is the "roll subsidence" and arises from the heavy damping of roll motions by the wings. The third mode, $\omega_{D R}$, represents a damped oscillation, the subseript $D R$ standing for "Dutch roll". This is 
primarily an oscillation in yaw angle due to the action of the vertical tail acting as a weathervane. Dihedral (anhedral) effects induce oscillatory motions in both roll and sideslip. Damping of the motion is provided mainly by the vertical tail and drag of the wings and struts, due to the differential airspeeds accompanying yaw rates.

The lateral behavior of the 1903 'Flyer' is generically the same as conventional aircraft which normally can be characterized by these modes. However, the spiral mode is unusually unstable, the amplitude doubling in about 2.5 seconds. This rapid growth is due largely to the anhedral. Partly because of the low speed and partly because of the low directional stability compared with the large yaw inertia, the period of the Dutch roll oscillation is relatively long, roughly 4.8 seconds. It is poorly damped due to the relatively small vertical tail and hence small damping in yaw.

Suppose that the pilot wishes to obtain a bank angle equal to ten degrees, which he observes as the angle between the horizon and the canard reference line. As a control law we assume that the pilot operates the warp control by an amount proportional to the difference error between the desired bank angle and that actually observed; the constant of proportionality is the pilots roll gain, $K_{p}$. Two cases are analyzed: pure warp, with no deflection of the rudder; and interconnected warp/rudder, corresponding to the control system in the 1903 'Flyer'. The locus of lateral roots can be calculated for the two cases, shown in Figure 21. For increasing gain, the roots corresponding to the spiral mode and roll subsidence move towards each other on the horizontal axis and then depart vertically, representing the formation of a heavily damped "spiral-roll" mode whose dynamics characterize the major portion of the response in roll.

More interesting is the dependence of the Dutch roll "nuisance" oscillation on the gain. For the case of pure warp, Figure 21(a), this becomes marginally damped for a reasonable value of the gain, $K_{p}=1.0$ (degrees of warp for each degree) of perceived error. The time history for a command of 10 degrees bank angle for a turn entry is shown in Figure 21(a). Large oscillations of bank angle, heading rate, and sideslip make this a wallowing motion nearly impossible to control and wholly unsatisfactory for practically flying. It is mainly due to the combination of anhedral and uncompensated adverse yaw.

When the rudder deflection is linked to the warping, thereby cancelling the adverse yaw, the result is a turning maneuver which is quite acceptable. The closed loop damping is now much higher - the filled square in Figure 20(b) lies well to the left of the vertical axis. The much improved response in time appears in Figure 21(b). Now the bank angle tends to a constant value, albeit not equal to the desired value (10 degrees) within the time scale shown. There is a fairly large angle of sideslip, so it is a sloppy uncoordinated turn, but surely possible. Thus the interconnection of the warp and rudder is an essential feature of the 1903 'Flyer'.

As the Wrights discovered in 1905 , satisfactory control is achieved only by warp and rudder coordination more complicated than proportional interconnection. It has often been stated, incorrectly, that the Wrights abandoned their interconnected warp and rudder. In their 1905 airplane, with the pilot sitting upright, they put both rudder and warp controls on a single stick. Lateral hand motion caused warp, while foreand-aft motion deflected the rudder. Consequently, any desired proportion of warp and rud- 
der could be produced by operating the stick in a suitable diagonal path. Far from abandoning warp/rudder interconnection, the Wright Brothers ingeniously provided a ratio instantly adjustable according to the trim speed or angle of attack. The data suggest the need for this flexible control.

No contemporaries of the Wrights possessed such a thorough appreciation of the details of turn coordination. Our analyses of the dynamics verify the soundness of the Wrights' concepts for lateral control. The results give us even more respect for their ability to accomplish nearly perfect turns, a problem which still plagues designers of aircrait flying at high lift coefficients.

In 1903, the Wrights understood well the subjects of structures, performance and control; their understanding and practice exceeded that of their contemporaries. It seems clear from analysis of our wind tunnel data, combined with the documented characteristics of their engine and the 1903 airplane, that the Wrights must have paid much attention to the performance problem, e.g. in choosing their wing area to achieve a good stall margin and in selecting the correct wing incidence and camber.

They had learned from Lilienthal that to design a successful airplane they also had to learn to fiy. What they added to that lesson was an effective control system, unquestionably their greatest contribution. From the beginning of their work they knew that they had to control rolling and not just pitching as their contemporaries had emphasized. Later they discovered that they also had to control yaw motions, that eventually made the 1903 'Flyer' manageable.

There was much the Wrights did not understand well, mainly subjects which were not clarifed until many years later. Perhaps the greatest gap in their knowledge was the theory of dynamic stability. Without that they could not formulate precise ideas of inherent stability in contrast to mere equilibrium.

Their 1903 'Flyer' was severely unstable statically, and barely controllable by modern standards of piloting. They detected the most serious difficulties during flight tests in 1904 and 1905 , but could correct them only by trial-anderror: they had no guiding theory. For example, they had deliberately used negatively arched wings to combat the tendeney for lateral gusts to force them into the hill while gliding. Our analysis of the dynamics has shown that as a result of the negative dihedral, the spiral mode was so strongly unstable as to be marginally controllable. The Wrights spent nearly a year at Huffman Prairie before they removed the negative dihedral in 1904. They had been treating the insta bility as a problem of lateral control, but it was in fact a problem of lateral dynamics. Similarly, in 1904 they mistakenly moved the C.G. back (more unstable) to obtain smoother longitudinal flights, before correctly moving it forward.

The Wrights' emphasis on control unquestionably flowed from their experience with bicycles. They knew that their airplane need not be inherently stable to be flyable. Their creation of the first practical aircraft proved their principles. It was not a very good airplane by modern handling standards but it was clearly good enough!

\section{The Wrights and European Aviation} $1903-1908$ *

While the Wright Brothers had rapidly progressed from a kite to powered flight, French* aeronautics was nearly stagnant and there was

* Most of the material in this section has been extracted from reference 6 . 
no activity elsewhere. Ferdinand Ferber had also started with kite/gliders, in 1898, but his first four were nearly complete failures. He had not made good copies of Lilienthal's gliders - for some unknown reason, Ferber even left the tail off - and he had no idea of roll control.

In January 1902, Ferber received from Chanute a copy of an article by Wilbur describing the Wrights' 1901 gliding tests. By June, Ferber had constructed his \# 5, a crude imitation of the 1901 glider: it was correctly built as a biplane Pratt truss with a moveable canard, but there was no roll control. That introduced the Wrights' basic configuration to Europe but not until after the Wrights flew in 1908 did anyone else fully grasp the idea of control. No other inventor realized that to make a successful airplane it was not enough for the pilot to be able only to cause the machine to go up and down. Even though Chanute knew that the Wrights warped their wings, and reported the fact both in lectures and papers (in France as well as the U.S.), he too did not understand its purpose.

Because he was a commissioned officer, Ferber did not have as much time and resources as he might have liked for his experiments. But his military superiors did give him support and he was able to continue his work. By June 1903 he had his airplane \#6, mounting a six horsepower engine driving two counter-rotating propellers on his glider \#5. He tried testing the craft on a huge rotating arm; that was a dismal failure, but did convince him that the power was inadequate for flying.

Chanute visited France in March 1903 and spent much time speaking about the Wrights' success. Ferber offered, through Chanute, to take flying lessons from the Wrights, and to purchase one of their gliders, but they refused. Be- sides working intermittently on his aircraft, Ferber spent much time popularizing the idea of heavier-than-air flight primarily to try to make France the birthplace of the airplane. He did succeed in generating enthusiasm and support for his cause. He truly deserves the credit for beginning the French community of aviators who so successfully learned from the Wrights in 1908-9 and quickly became the leaders in practical aviation.

In January 1904 Ferber gave a public lecture to the Lyon chapter of the French Auto Club. His subject was "Progress in Aviation with the Glider since 1891", later published as a monograph in December 1904. One of the listeners was a young architect, Gabriel Voisin, who immediately committed himself to aviation. Voisin moved to Paris to begin his work; two years later he established the first organization for constructing and selling aircraft.

Voisin went to Paris to work with a wealthy lawyer/sportsman, Ernest Archdeacon, who had become interested in aviation partly by Ferber's efforts. With Archdeacon's financial support, Voisin built a copy of the Wrights' 1901 glider which he and Ferber test flew in April 1904. They made short glides but, still not having roll control, they were obviously far behind where the Wrights already were in 1900.

It was during this time that the notion of the "Wrights' bluff" began. Many, particularly Archdeacon, felt that, judging by the difficulties the French experimenters were having, the Wrights could not possibly have accomplished what they claimed. (News of the 1903 powered flights had reached France soon after the event and Chanute had spoken at length about the gliding tests of 1901 and 1902). Moreover, it was unthinkable that two Americans could beat the French who, after all, had a long tradition of 
aeronautical successes including, most recently, the first navigable powered balloons. Only Ferber did not have such haughty attitudes, and believed the Wrights.

Nevertheless, the French seemed to have so underestimated the difficulty of making a successful flying machine that they could scarcely bring themselves to formulate carefully the problems to solve. To encourage progress, Archdeacon funded three prizes announced in October 1904: the Archdeacon cup for the first powered flight of 25 meters in France; a prize of 1500 francs for the first powered fight covering 100 meters; and the Deutsch-Archdeacon prize of 50,000 francs $(\$ 10,000)$ for the first flight in a closed circuit of one kilometer in Europe. Chanute sent a copy of an article announcing the prizes to the Wrights. They were amused both by a quotation attributed to Ferber that "the airplane need not be completed in America", and by the knowledge that they were indeed much ahead of the French. In response to his request, they sent regrets that their full schedule did not permit a visit by Ferber.

Early in 1904, Ferber accepted a post at the French army balloon station at Chalais-Meudon near Paris. There he was given full support for his experiments - including a workshop and a mechanic. He continued testing his glider \#5 and \#6 without the engine, and even experimented with "jibs" mounted on the wing tips to try to get some lateral control. However, he finally satisfied himself with dihedral for stability in roll and a vertical tail - but no yaw control. He had so much trouble controlling his canard in pitch that he added a Pénaud tail for longitudinal stability. Thus he introduced the configuration the biplane with both forward and aft tails that was widely used in France for several years and also in the U.S. by Glen Curtiss and Alexander Graham Bell who in 1907 together founded the Aerial Experiment Association (AEA).

Ferber added wheels and a twelve horsepower engine to his double-tailed biplane design and constructed his airplane \#7. On 27 May 1905 he executed a powered glide, reducing the glide ratio from 1:5 to 1:7. That was the first "powered flight" in Europe but it did not begin with a take-off: Ferber had launched himself from a clever arrangement of pylons and ropes. That event was Ferber's chief technical "first". His career from then on was largely devoted to popularizing and writing, although he never ceased flying until his death. His airplane \#9 (Figure 22) ninally gave him successful Rights. It had both aft and forward tails, the configura tion copied by many of his contemporaries, including Curtiss in the U.S. (Figure 23).

But there was other important activity in Paris. Voisin continued with Archdeacon's support. He built a biplane after Ferber's design, with nearly 540 square feet of lifting surface. Towed by a speedboat on the Seine, it reached an altitude of 50 feet during a flight of about $\mathbf{4 5 0}$ feet. More importantly, the event was witnessed by Louis Blériot who then ceased his dabbling with ornithopters and began seriously to work with fixed-wing aircraft.

Blériot was a graduate engineer and a successful manufacturer of automobile accessories. Consequently he had his own financial resources and began his experiments with aircraft by commissioning Voisin to build him a glider. In July 1905 it was towed on the Seine, exhibited a severe instability, crashed and sank.

That was the beginning of Blériot's aviation career. Eight more designs finally led to the Blériot IX, the aircraft that Blériot piloted 
across the English Channel four years later.

Towards the end of 1905, Voisin left Archdeacon, and with Blériot bought the Surcouf workshops (previously used for making balloons) to found the first airplane factory. After an unsuccessful attempt to test his glider on Lake Geneva, Archdeacon ceased his involvement in the construction of aircraft. He remained active in the Aero Club and generally as a promoter of aviation in France.

The designer of the tow boat for the Blériot's test on the Seine, Leon Levavasseur, became an important figure in the growth of French aviation. A superb mechanical designer and $m a-$ chinest, he had obtained financial support from a wealthy manufacturer of electrical equipment, Jules Gastembide, whose daughter's name, Antoinette, was attached to their products. An airplane he built in 1903 was a failure and Levavasseur then concentrated on developing lightweight engines for aircraft. He soon had brilliant success, with a $20 \mathrm{HP}$ engine weighing only four pounds per horsepower which powered his boat. Levavasseur eventually produced two engine designs for aircraft: one delivered 24 HP (first built at Ferber's request) and the larger produced 50 HP. Thus, beginning in 1906, the French had the world's best aircraft engines. Levavasseur later produced the elegant and successful monoplane, the Antoinette. The design was partly due to Ferber who had a brief association with Levavasseur's firm in 1907-08.

Early in 1905, another event occurred that deflected French attention from the Wrights' use of roll control. Robert Esnault-Pelterie (later a pioneer in French rocketry) gave a lecture describing his experiences with his own reproduction of a 1902 Wright glider. His purpose had been to determine whether he could duplicate the
Wrights' claimed performance. Partly because the machine was poorly constructed, he was unable to do so, a conclusion that strengthened French skepticism of the Wrights' work - three years after the fact. Esnault-Pelterie found poor results with the wing-warping for roll control and proposed the use of moveable horizontal surfaces as an alternative scheme. Thus he invented ailerons and clearly described their use. The fundamental contribution seems to have been entirely ignored in 1905. Two years later Curtiss and Bell adopted the idea for their powered aircraft.

During most of 1906, French aeronautics produced only failures. Then in the fall, Alberto Santos-Dumont (already a French hero for his airship fights) got off the ground in his 14 bis, inspired by the Wright canard configuration. It had a lengthened and fabric covered fuselage; the wings were constructed in the form of an elongated box-kite and an exaggerated dihedral angle. With 50 HP Antoinette engine driving a pusher propeller, Santos-Dumont made the first powered flight in Europe, covering 60 meters on 23 October, thereby winning the Archdeacon cup. Three weeks later, after installing crude ailerons, Santos-Dumont made 220 meters and won the Deutsch-Archdeacon prize. Those fights caused a considerable stir in France - even though they can by no measure be called examples of controlled flying.

At the end of 1906, Blériot left Voisin, and after a brief period with Société Antosinette he formed his own group, and eventually founded his firm. Serious work with aircraft expanded rapidly in 1907 . Santos-Dumont's flights had been highly publicized and the supporters of French aeronautics were now optimistic that they were on the right track. Already two public 
flying areas were available in Paris: a portion of Bagatelle, an estate in the wooded area of Bologne where Santos-Dumont had flown; and the field in Issy-les-Molineux, or "Issy", a large flat area intended primarily for military parades. By the end of 1907, the grand expanse of Issy had become the training ground for France's aviation pioneers.

While the French inventors were painfully slow to realize the fundamental need for roll control, they did have one enormous advantage: their engines. The availability of Levavasseur's Antoinette engines made possible the advances of French aviation in 1907 and 1908. That the flying in Paris could not match the Wrights was not for lack of powerplants.

Despite their failure to follow a systematic program paying proper attention to basic principles, the French made significant progress. Neither ailerons nor wing warping were widely used, dihedral being accepted as adequate. Thus, turns were executed by skidding. Rapid deflection of the rudder causes one wing to move faster than the other. That creates a difference in the list on the two wings, giving a roll moment that banks the airplane; thus the required force directed to the center of the turn is produced. It's an awkward, dangerous way to turn and lacks precision. Nevertheless, it was how the French flew and by the summer of 1908 , Voisin and Blériot aircraft were making flights longer than twenty minutes. (Still far short of the Wrights' best 38 minutes in 1905).

More significant for the future of French aviation was the experience gained by the community of aviators. Many became famous pilots. Others are familiar as manufacturers of aircraft in World War I and later: Blériot, Breguet, Esnault-Pelterie, Farman and Voisin. Ferber's dream came true: France was first, not as the birthplace of the powered aircraft, but in flying achievements and production of aircraft.

After their first flights in 1903, the Wrights knew they had much to accomplish to have a practical aircraft. They worked for two years, test flying at Huffman Prairie in Dayton. In addition to building larger and more efficient engines, they significantly improved the flight dynamics of the aircraft. They increased the areas of both the vertical tail and the canard, and moved them further from the wings, thereby improving the pitch and yaw control and stability. Although they eventually discovered that they should move the center of gravity forward, the final version of the aircraft in 1905 was still unstable in pitch, having negative static margin of about 8 percent with a single pilot on board. ${ }^{28}$ The lateral characteristics were significantly better due to the shift from anhedral to slight dihedral. With independent warp and rudder controls, the aircrait was a fully maneuverable machine.

After they removed the anhedral and uncoupled the warp and rudder, the Wrights discovered the last problem thay had to solve to have a practical airplane: stalling in a turn. Between September 28 when they first flew with the independent controls, and October 5 when they flew for 38 minutes, the Brothers learned how to re cover from a stall. Wilbur's description in his summary of the experiments in 1905 (Reference 5 , pp. $519-521$ ) is a superb statement of the problem and its solution:

The trouble was really due to the fact that in circling, the machine has to carry the load resulting from centrifugal force, in addition to its own weight, since the actual pressure that the air must sustain is that due to 
the resultant of the two forces... When we had discovered the real nature of the trouble, and knew that it could always be remedied by tilting the machine forward a little, so that its flying speed would be restored, we felt that we were ready to place fiying machines on the market.

What a magnificent achievement! In six flying days from September 28 to October 5 , 1905, the Wright Brothers solved their last serious problem, had a practical airplane, and now set out to sell their invention.

For non-technical reasons, the time from October 1905 to August 1908 is the most intriguing period of aeronautical history. It was dominated by the Wrights because they knew they had something nobody else had, and they were content simply to state the fact without proof. In the absence of public demonstrations, most of the rest of the world was unconvinced - except for Chanute, Ferber and several other French who believed the quite detailed information released by the Wrights in late 1905 and early 1906. While the Wrights devoted their efforts to obtaining acceptable contracts, other inventors, chiefly French, continued their awkward experiments. The aeronautical tortoise and hare race finally ended with the Wrights' dramatic flights at Le Mans and Fort Myer in 1908 - the hare had won.

During 1905 the Wrights devoted most of their time to developing their aircraft. But already in the early part of the year they had contacted the U.S. War Department to offer their machine for sale. Their confidence was premature, being based on their 1904 test results which, the Brothers knew, showed that the airplane still required much improvement. They could not yet execute turns without difficulty. But they also knew that they could solve their problems so they initiated their program to sell their invention.

Their purpose was to reach agreement to license their airplane for military use by national governments, the U.S. holding a preferred position. They would retain the rights for commercial exploitation. From the beginning of their marketing program, the Wrights sought signed contracts agreeing to the sale before they demonstrated the airplane. The customer would be protected by specifying minimum performance to be met by the Wrights before the sale would be completed. Their negotiations dragged on for more than two years mainly because prospective buyers wanted demonstrations before they would sign contracts; and partly because of differing views of the performance to be met within the time and price specified.

Ferber was probably the first to try to purchase a Wright powered aircraft when he wrote the Brothers in January 1904 asking the price of the 1903 'Flyer'. They replied that it was not sufficiently developed to be sold. In the fall of 1904 a British offcer from the Royal Aircraft Factory (which at that time made balloons and dirigibles) sought a proposal from the Wrights to sell to the British government. They did not respond, but through their congressman they wrote in January 1905 to the U.S. Secretary of War to determine if there was interest in their flying machine which they described as capable of being "fitted for practical use". Their letter was forwarded to the Board of Ordnance and Fortification who replied that they could agree to no financial commitments until the machine had been "brought to the stage of practical operation without expense to the United States", which to them seemed not to have been accomplished. 
The Wrights took that reply as expression of no interest. Then in February of 1905 they received a letter from the British War Office asking them to submit a formal proposal. To this they responded that they could provide a machine "capable of carrying two men of average weight and supplies of fuel for a flight of not less than fifty miles; its speed, when flying in still air, to be not less than thirty miles per hour ..." They would agree that the British could refuse to accept the airplane if no flight exceeded ten miles. The price was set at $\$ 2500$ per mile, so the Brothers anticipated receiving at least $\$ 25,000$ and probably more than 1.2 million dollars based on their proven performance. Two dozen letters were subsequently exchanged between the Wrights and the British during the following two years, but no agreement was reached. Neither the price nor the promised performance were obstacles: the sticking point was the British insistence upon witnessing flights before they would sign a contract.

Ferber wrote to Wilbur in May 1905 requesting a quotation for purchase of their airplane. Having been turned down already by their own government and by the British, the Wrights had no interest in pursuing the matter at that time. Not until October did they reply to any requests for proposals.

Although they shifted their position in minor respects as they searched for buyers, the Wrights never deviated much from their own basic guidelines. First they wanted to deal with governments. They foresaw the military importance of their invention and felt that they could best realize the value of their labors by selling for that purpose. Commerical possibilities seemed at the time to be limited to sportsmen and exhibitions.
Second, they were concerned about protecting their discoveries for themselves and their future customers. They had applied for a U.S. patent in 1902 , but it was not granted until 1906. In 1905 they were also seeking foreign patents, but in any case they did not trust the patent procedure. They were convinced that secrecy was the only sure way of preventing theit of their invention. That is the primary reason that the Wrights didn't fly at all for so long and even when they did fy later, they carefully painted various wooden parts with aluminum paint to try to disguise the structure of the airplane.

On the other side, the Wrights' potential customers were cynical of their claims, mainly because no public fiying demonstrations since Lilienthal had given any basis for confidence. Both Lilienthal and Pilcher had been killed. Langley had been able to produce only two wellpublicized take-off failures in September and December of 1903. There was no other known aeronautical work in the U.S.; nothing had happened in Britain since Pilcher's death, and there was no activity in Germany. Thus it is not surprising that the bureaucracies were cautious about spending money on flying machines.

In March 1905, Archdeacon wrote the Wrights, offering to visit the U.S. to witness their work and confirm their claims. Or, they could "come to give us lessons in France". He also mentioned the Deutsch-Archdeacon prize which the Wrights could presumably win easily. The Wrights replied that it was too soon for them to give a public demonstration. Archdeacon therefore discounted the Wrights claims, reinforcing his belief that France would be the home of the first practical airplane.

Four days after their 38 minute flight on 5 October, the Wrights briefly summarized their 
success in a letter on 9 October to Ferber, expressing also their interest in contracting rights to their airplane. He immediately responded, again offering to buy their airplane but ingenuously cautioned that in view of his own progress in May (his powered glides) an agreeable price would now be lower.

The Wrights promptly replied on 4 November, congratulating Ferber on his work: "Probably no one in the world can appreciate as much as we can, the importance of your results... France is fortunate to have a Ferber". They noted that France would therefore be ir. $z$ better position to make practical use of the Wright airplane, so they would offer a reduced price of one million francs $(\$ 200,000)$ to the French government. This would be paid after a demonstration flight of at least 50 kilometers in one hour or less. Although Ferber didn't know it, the price was indeed well below that which the Wrights had offered to the British.

Ferber was unable to convince his superiors that the Wrights had done what they claimed; the army had no interest in dealing for their airplane. After mustering more evidence, including a report from a trusted American in Ohio, he was able to persuade Letellier, a wealthy contractor and publisher of the Paris newspaper Le Journal to talk with the Wrights. With his participation in the beginning of Fordyce's mission, Ferber's direct influence on negotiations between the Wright Brothers and France ceased.

Letellier sent his secretary Arnold Fordyce to Dayton. He and the Wrights came to terms on December 30, 1905: the price was $\$ 200,000$, with a $\$ 5,000$ bond to be posted by 5 February 1906. The Brothers promised to furnish an airplane capable of flying 160 kilometers carrying one person.
With Fordyce's option in hand, Letellier contacted the Minister of War who agreed to enter serious negotiations with the Wrights. Growing indications of trouble with Germany contributed to the French interest: the flying machine looked like a promising instrument for scouting. However, during the next few months, as the French pressed for higher performance, and the Wrights raised their demands, the political crisis in Europe cooled and so did the pressure for a military airplane. In the end, the deal fell through and the Wrights collected their $\$ 5,000$ bond in October 1906.

During the summer of 1906 , the Wrights were contacted several times for possible sales, notably by British representatives, but nobody would accept their terms. A New York businessman, U.D. Eddy, learned of their flying machine from newspaper reports and visited the Wrights in November. The chief result of the meeting was the Wrights' decision not to continue handling all negotiations by themselves. That forced them to leave Dayton and meet with their potential customers, but it would still take them more than a year to sign contracts.

Eddy was impressed by the Wrights' integrity and arranged for them to meet with the Charles R. Flint Company, promoters and bankers in New York. Wilbur and Orville went to New York in December. By the end of December, agreement had been reached that the Flint firm would be the business representatives for the Wrights in Europe, in return for $20 \%$ of the profits up to $\$ 500,000$ and $40 \%$ of larger amounts. The Wrights would continue themselves to handle all contracts in the United States.

In May 1907, Wilbur sailed for Europe to meet Hart $O$. Berg, a Flint associate who had been selling American inventions on the Conti- 
nent since 1899. Despite the widespread skepticism about the validity of his claims, Wilbur was well-received in France. He at last met Ferber and on one occasion reviewed troops with President Fallieres and Premier Clemenceau.

But even with Berg's help the negotiations dragged on, both with Letellier and the War Ministry in France and elsewhere. Orville came to Europe in July, at a time when things looked hopeful, but the progress stopped. The Brothers returned to the U.S. in November - six months in Europe had produced no results.

A separate syndicate had been formed by a financier, Lazare Weiller, in July. Initial discussion with Berg had led nowhere. But in early 1908, the War Ministry became more flexible, and Berg and Weiller finally reached agreement with terms substantially different from those specified in other contracts the Wrights had been discussing. The syndicate would buy the Wrights' French patents and all rights to manufacture, sell, and license Wright airplanes in France. They would form a new company, La Compagnie Générale de Navigation Aérienne, after the Wrights had given their demonstration flights and had trained French pilots.

In return the Wrights would receive $\$ 100,000$ upon delivery of the first machine, $50 \%$ of the founders' share of stock and $\$ 4000$ each for four additional aircraft. Wilbur went to New York in mid-March to discuss the proposal with the Flints. He agreed and on March 23, the Wrights learned that Weiller had accepted. Thus the deal was finally closed, causing Wilbur to fly publicly for the first time in France, five months later.

Independently of the European talks, the Wrights had continued their efforts to interest the U.S. Army in their machine. They were contacted by the Board of Ordnance and Fortificar tions after Herbert Parsons, a Republican leader in New York City, brought the Wrights' Aying machine to the attention of President Roosevelt. They responded with their usual proposal: no demonstration before a contract had been signed, but nothing to be paid by the purchaser until satisfactory demonstration flights had been completed. The price would be $\$ 100,000$ for one machine and pilot training, the same offer they had made to the British in July, 1906, with no success.

The Board still insisted on seeing the airplane before they would write a contract, but the Brothers held their ground, writing in June 1907 "In view of the abundant evidence already available, we do not regard the actual sight of the machine a prerequisite to the formulation of terms of contract..." The differences could not be resolved, and there were no further communications until October when the Board again wrote the Wrights a letter which they answered from London. And again they insisted on the need to protect their rights, the price of the first machine being secondary.

However, due to the presence of a staff offcer, Lieutenant Frank P. Lahm, who had met and believed the Wrights, Wilbur was facing a more receptive customer when he visited Washington on his return from Europe to Dayton.

The Board had decided to advertise for bids to provide the Army with an airplane; the purpose of the meeting was to discuss the specincations of the airplane and conditions of sale. The advertisement was published on 23 December 1907, soliciting bids for an aircraft whose performance could easily be surpassed by the latest Wright Flyer: it should be able to fy for one hour carrying the pilot and a passenger, their total weight being at least 350 pounds; it must be 
able to make a ten mile test averaging at least forty miles per hour; and it must carry enough fuel to fly 125 miles. Prior to the publication, Wilbur had provided a few minor changes in the draft copy, and in response to the Board's query he answered "We are not prepared to give advice as to the time to be allowed between the issuance of the specifications and the submitting of bids. A very few days would be suffcient for us". Although it is probably going too far to say that the RFP was "wired", nevertheless the Wrights could not have placed themselves in a more favorable position to respond.

On January 27 , 1908, the Wrights submitted their bid for $\$ 25,000$, enclosing the necessary certified check for $\$ 2500$ required as a bond to show good faith. They also enclosed a photo graph of their 1905 aircraft, and drawings, which were of course to be kept confidential. The War Department accepted the Wrights' bid on February 8 , six weeks before the French contract was completed. The Army had issued their call for bids "really for the purpose of forestalling criticism and sounding public sentiment" (Wilbur). Reaction in the press was heavily negative. An editorial in the American Magazine of Aeronautics predicted "We doubt very much if the government receives any bids at all possible to be accepted." Surprisingly, 41 bids arrived, but only two besides the Wrights' contained the required bond, and both quoted a lower price. One of those bidders soon asked that his $10 \%$ deposit $(\$ 100)$ be returned and the govo ernment complied. The Army then decided to accept both remaining bids and purchase both aircraft if they met the specification. The other bidder was in fact bluffing: he had schemed to underbid the Wrights to win the contract, and then sub-contract the job to the Wrights.
Two weeks after the French contract had been agreed to, Wilbur and Charles Taylor, the Wrights' mechanic, left Dayton for Kitty Hawk to put their living quarters and work buildings in order. Orville arrived in late April with one of their 1905 airplanes. They had only minor difficulties resuming their flying and in less than three weeks they were satisfied with preparations for their demonstration flights. On May 21, 1908, Wilbur sailed from New York for Europe and Orville stayed in the U.S. to show the Army their machine. Ferber was there, at the Hunaudières racetrack, on August 8, when Wilbur's first demonstration so stunned the French aviators. They no longer doubted the Wrights' claims. They had been thoroughly beaten. But the hard work at Issy had prepared them to learn from the Wrights, correct their errors and press on to take the advantage.

During the eight months starting in August 1908, the Wright airplane (Figure 24) dominated aeronautical news. Wilbur and Orville showed the world what they could do with the machine they had perfected in 1905. Their flights pro duced a continuing stream of new world records, executed with techniques and skill that were to tally new to the French. With their dazzling public performances the Wrights convinced all Europe: they could now sell their airplanes as fast as they could build them. The were immersed in "big business".

Overcoming their pride, the aviators in Paris learned quickly from the Americans. They had watched at Le Mans, and now understood the real function of wing warping as a means of con. trol and not merely as an aid to maintaining lateral equilibrium. The inventors increased their efforts, now with strong support from the public press in response to the obvious advantage held 
by the Wrights.

In December, the annual automobile show, Salon d'Automobile, had for the first time an aviation section. Salon d'Aéronautique showed a bit of 19th century French aeronautics, some spherical balloons, dirigibles and sixteen modern airplanes: Lazare Weiller's Wright aircraft and fifteen French examples. There were two Voisins (Delgrange's and Farman's, Figure 25) an Antoinette, (Figure 26) and Santos-Dumont's No. 20, the Demoiselle; Bleriot had his airplanes IX, X and XI (Figure 27); Esnault-Pelterie had a new design with wing-warping and his own engine; Ferber showed his No. 9 (Figure 22). In its review of the show, L'A érophile once again praised Ferber's early belief in the Wrights, his inspiration for Gabriel Voisin and his part in the design of the Antoinette monoplane.

Ferdinand Ferber died in a landing accident at a flying meet in Boulogne, on September 3, 1909, the second French fatality in powered flight. He lived just long enough to see that his early relationship with the Wrights and his efforts to popularize the new aviation technology had been instrumental in founding French aeronautics. The Wrights had solved the problem of mechanical flight but France had the community of inventors and aviators prepared to exploit the Wrights' discoveries.

\section{References}

1. Bettes, W. H., and Culick, F. E. C., "Report on Wind Tunnel Tests of a 1/6-Scale Model of the 1903 Wright Flyer Airplane," Guggenheim Aeonautical Laboratory, California Institute of Technology, GALCIT Report 1034, February 1982.

2. Culick, F. E. C., and Jex, H. R., "Aerodynamics, Stability, and Control of the 1903
Wright Flyer," in The Wright Flyer - An Engineering Perspective, Smithsonian Institute, December 1986.

3. Jex, H. R., and Culick, F. E. C., "Flight Control Dynamics of the 1903 Wright Flyer," AIAA 12th Atmospheric Flight Mechanics Conference, 1985, AIAA Paper No. 85-1804-CP.

4. Angelucci, E., The Rand McNally Encyclopedia of Military Aircraft 1914-1980, The Military Press, N.Y., 1981, p. 29.

5. McFarland, M. (Ed.), The Papers of Wilbur and Orville Wright, New York: McGraw-Hill Book Co., 1953.

6. Culick, F. E. C., "Aeronautics, 1898-1909: The French-American Connection," Paper Delivered at a Meeting of The Society for the History of Technology, October, 1987.

7. Gibbs-Smith, C. H., The Invention of the Airplane (1799-1909), New York: Taplinger Publishing Co., Inc., 1965.

8. Gibbs-Smith, C. H., Sir George Cayley's Aeronautics 1796-1855, His Majesty's Stationary Office, 1962.

9. Pénaud, A., "Aéroplane Automoteur: Equi-

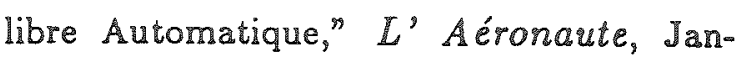
uary 1872, pp. $2-9$.

10. Lilienthal, O., Birdfight as the Basis for Aviation, Translated by A. W. Isenthal, Logmans, Grien, and Co., London, 1911.

11. Jarrett, P., Another Icarus: Percy Pilcher and the Quest for Flight, Smithsonian Institution Press, Washington, D. C., 1987.

12. Chanute, O., Progress in Flying Machines, M. M. Forney, New York, 1894.

13. Gibbs-Smith, C.H., Clement Ader: His Flight-Claims and His Place in History. 
Her Majesty's Stationer's Office, 1968.

14. Langley, S. P., Experiments in Aerodynamics, Smithsonian Contributions to Knowledge, Vol. 27, No. 1, 1891.

15. Langley, S. P., and Manly, C., (Ed.) Langley Memoir on Mechanical Flight, Smithsonian Contributions to Knowledge, Vol. 27, No. 3, 1911.

16. Lanchester, F. W., Aerodynamics, 1907; Aerodonetics, 1908, Archibald Constable \& Co., Ltd., London.

17. Turnbull, W. R., "Researches on the Forms and Stability of Aeroplanes," Physical Review, Vol. XXIV, No. 3, March 1907, pp. 285-302.

18. Bryan, G. W., and Williams, W. E., "The Longitudinal Stability of Aerial Gliders," Proc. Roy. Soc. of London, Vol. 73, 1904, pp. 101-116.

19. Bryan, G. W., Stability in Aviation, MacMillan and Co., Ltd., London, 1911.

20. Culick, F. E. C., "The Origins of the First Powered Man-Carrying Airplane," Scientific American, July 1979, pp. 86-99.

21. Moedebeck, H. W. L., Pocket-Book of Aeronautics, Translated by W. M. Varley, Whittaker \& Co., London, 1907.

22. Howford, J., "Vortex Lattice Computations of the Wright Flyer Loads," Douglas Aircraft Co., Personal Communication, December 1980 .

23. Dwyer, S. J., and Sanders, W. J., "1903 Wright Flyer Airloads Analysis," Douglas Aircraft Co., Working Paper, Personal Communication, November 4, 1980.

24. Wolko, H. S., "Structural Design of the 1903 Wright Flyer," in The Wright Flyer - An
Engineering Perspective, Smithsonian Institution, December 1986.

25. McRuer, D., Ashkenas, I., and Graham, D., Aircraft Dynamics and Automatic Control, Princeton University Press, Princeton, New Jersey, 1973.

26. Etkin, B., Dynamics of Atmospheric Flight, Wiley and Sons, New York, 1959, p. 352.

27. Jex, H. R., and Cromwell, C. H. III, "Theoretical and Experimental Investigation of Some New Longitudinal Handling Qualities Parameters," Report No. ASD-TR-61-26, June 1962.

28. Hooven, F. J., 'The Wright Brothers' Flight-Control System," Scientific American, December 1978, pp. 133-140. 


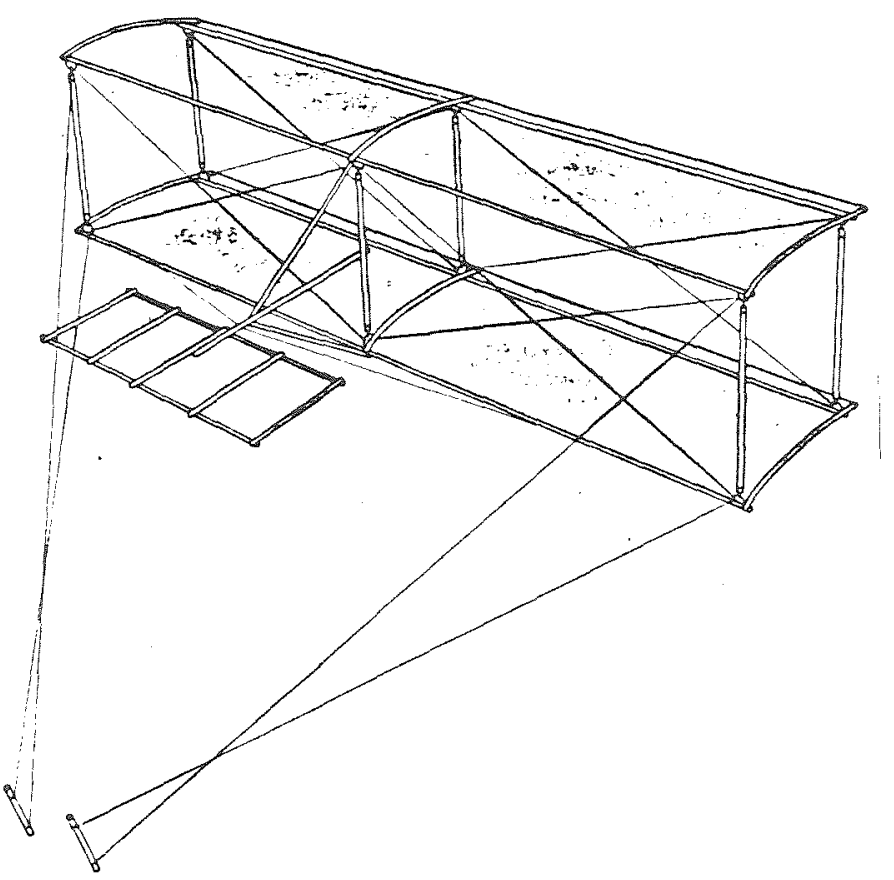

Figure 1. luby kite

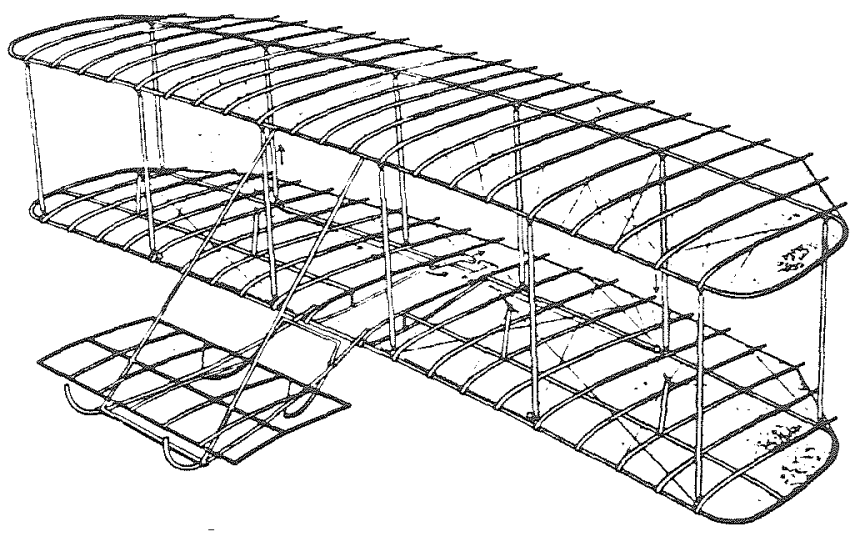

Figure 3. 1901 Glider

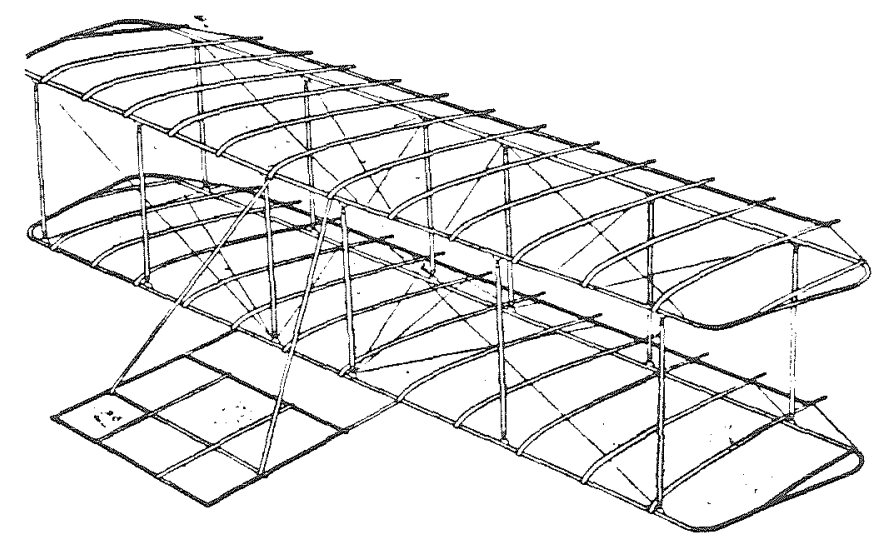

Figure 2. 1900 Kite/Glicier

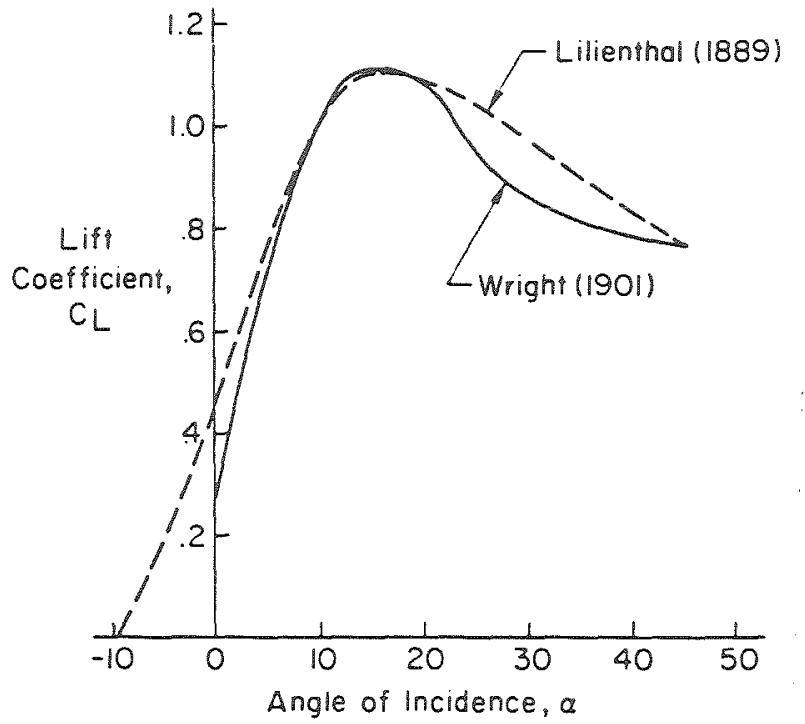

Figure 4. Comparison of Data for Lift Coefficient

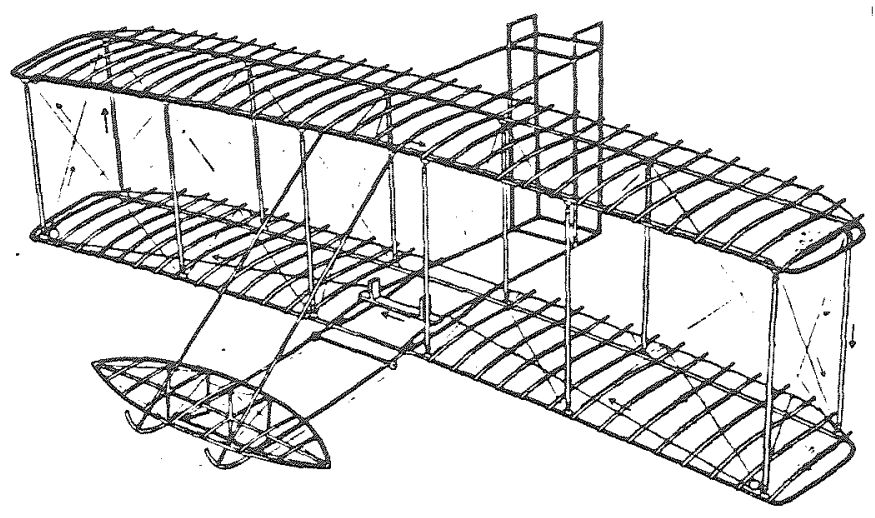

Figure 5. 1902 Glider 

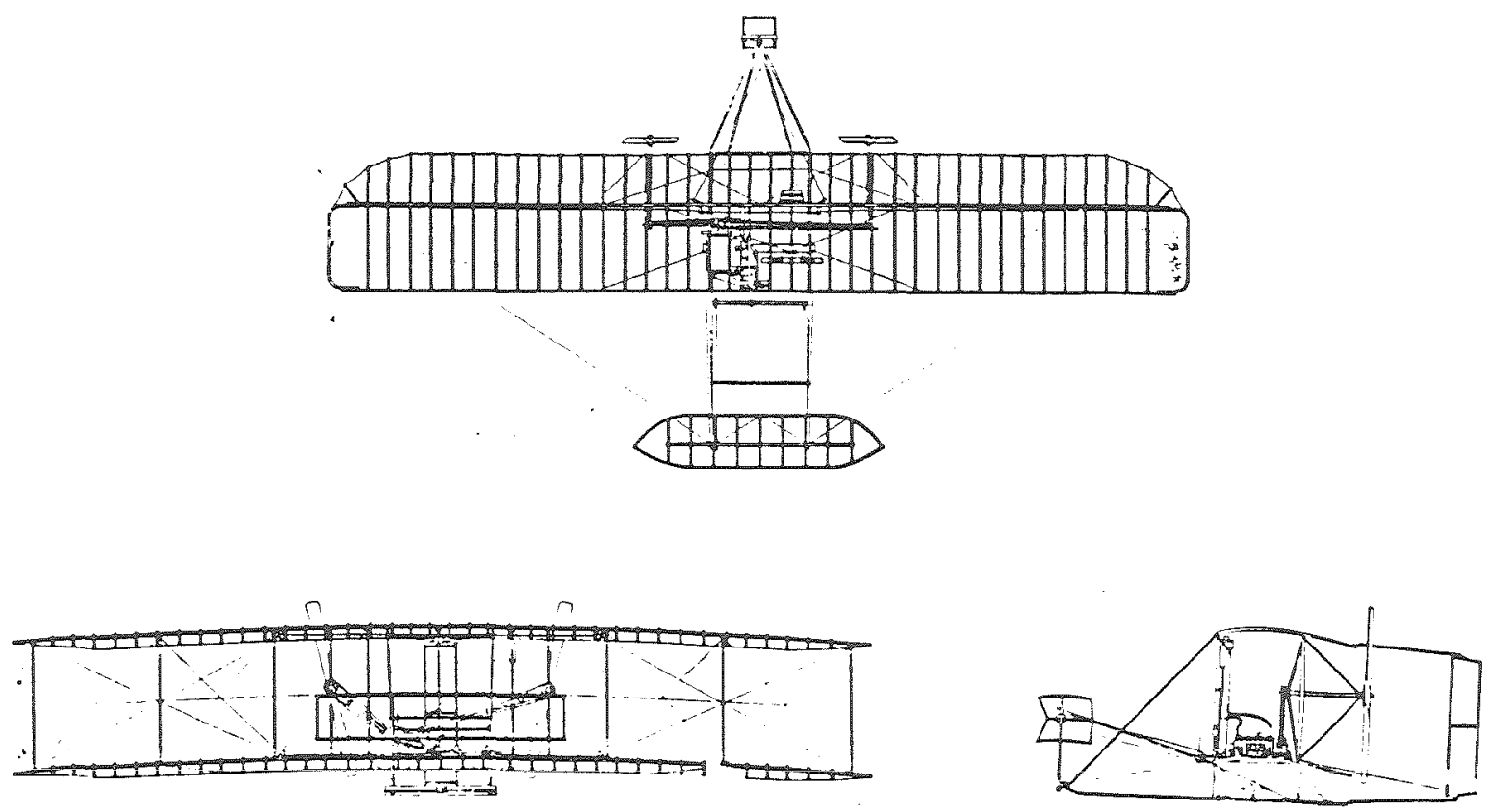

Figure 6. Igu3 reight ingei

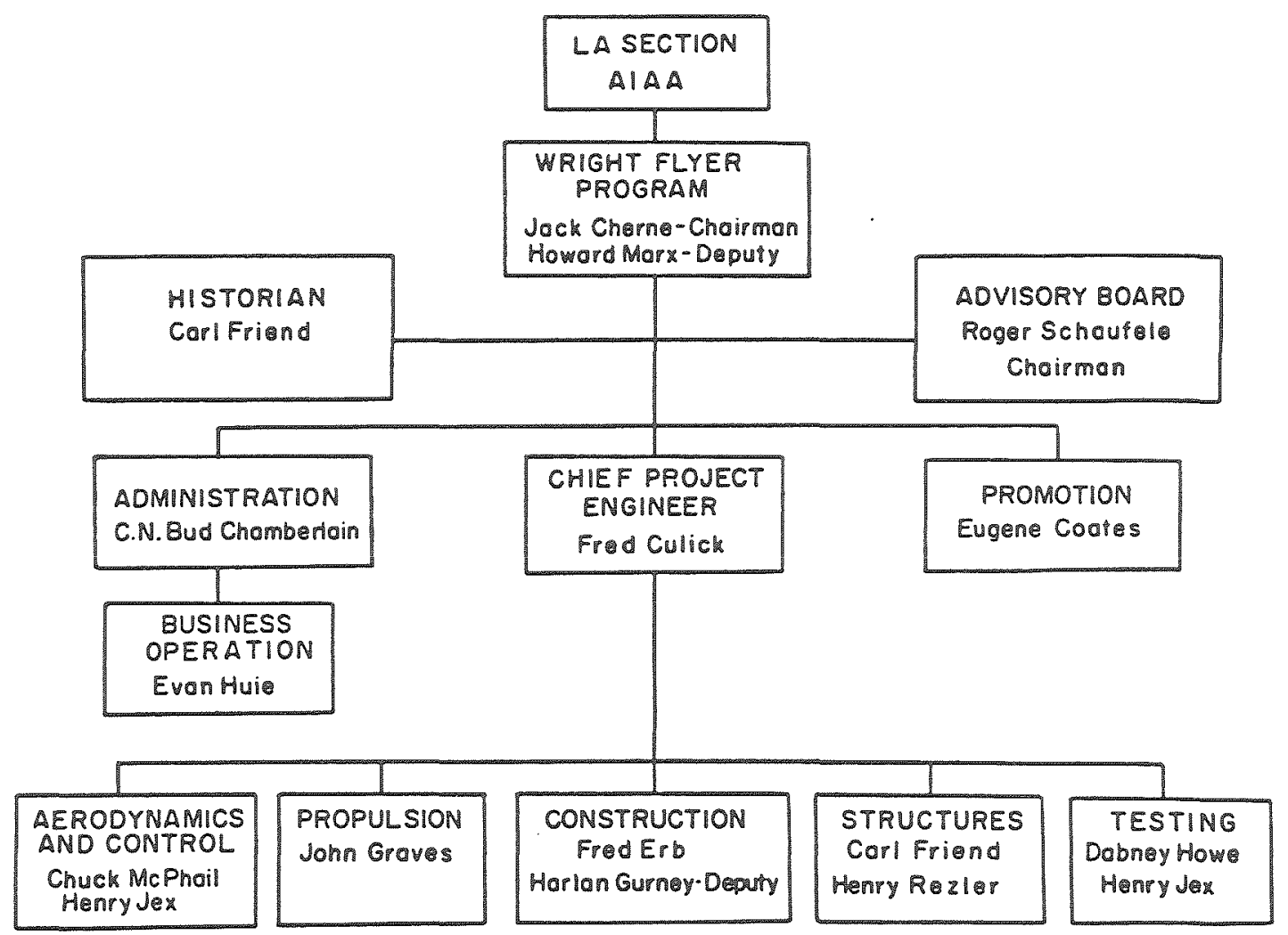

yigure 7. Cranization Chart, AIAA Wright Flyer Project 


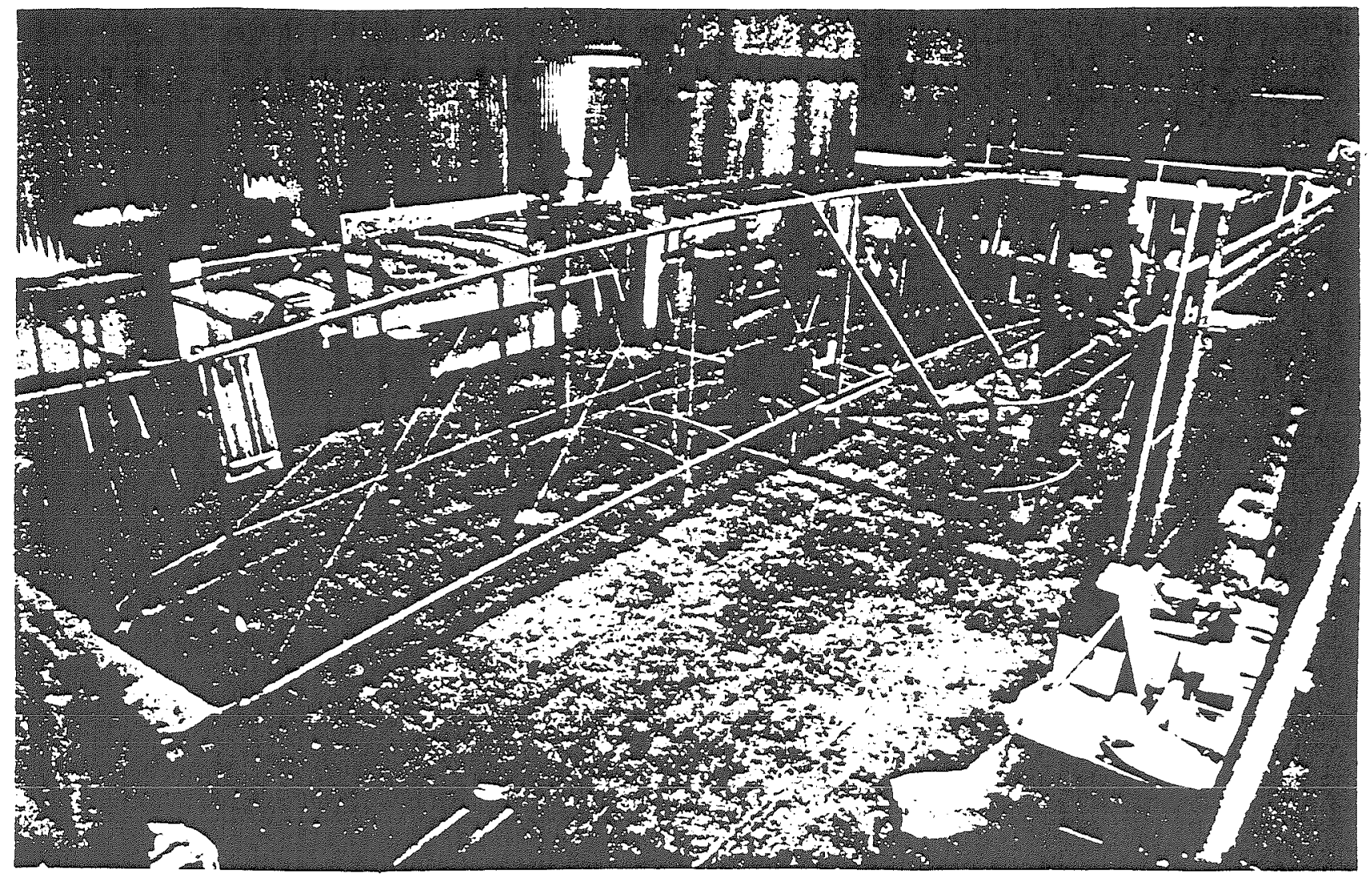

Figure 8. Assembled 1903 Flyer

Note: Arrow lengit: denores local $C_{L}$ (lifp/area)

\section{a) Stable (c.a. aheod of neutral point)}

- Center of grovily forward

- Forward surface stalls first-pilch down

- Recovery: "outomatic"; conirol with aff surface (unsialled)

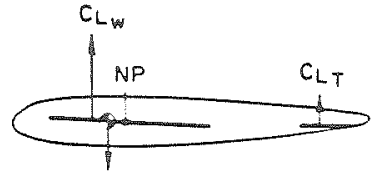

I) AR: Toll (PẼnoud)

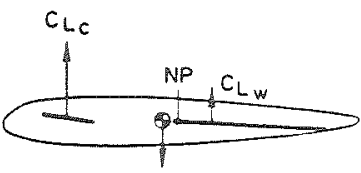

2) Conord (Puton)

b) Unstable (c.g. behind neutral point)

- Center of grovity off

- Apt supface siclis firsp-pitch up

- Recovery: control with forward surfoce (unstalled)

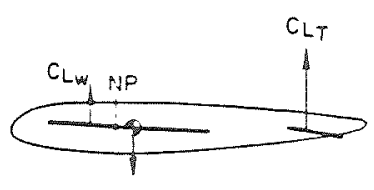

3) Alt Tail-Relaxed Stobility (Birds)

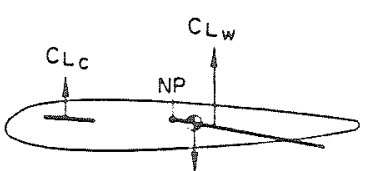

4) Conord (Wrignis)

Figure 9. Wing/Tail Configurations 


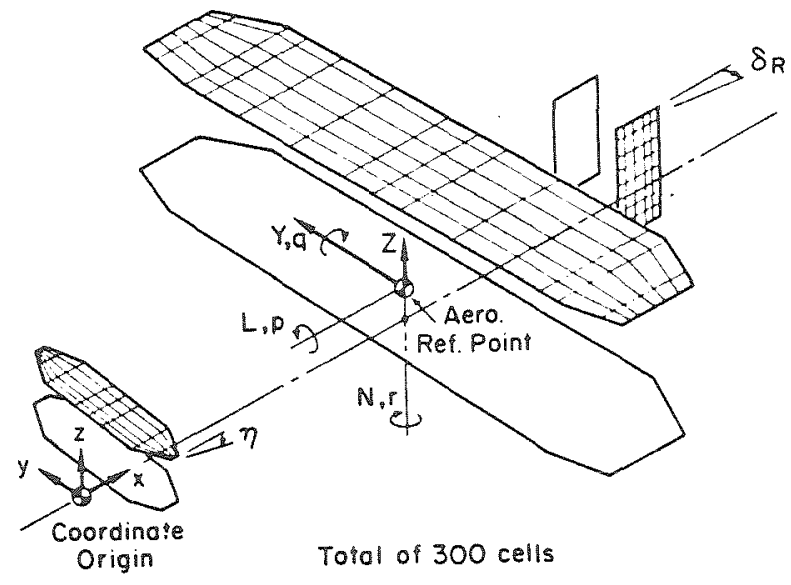

Figure 10. Approximation to the Wright Flyer For Vortex Lattice Calculations

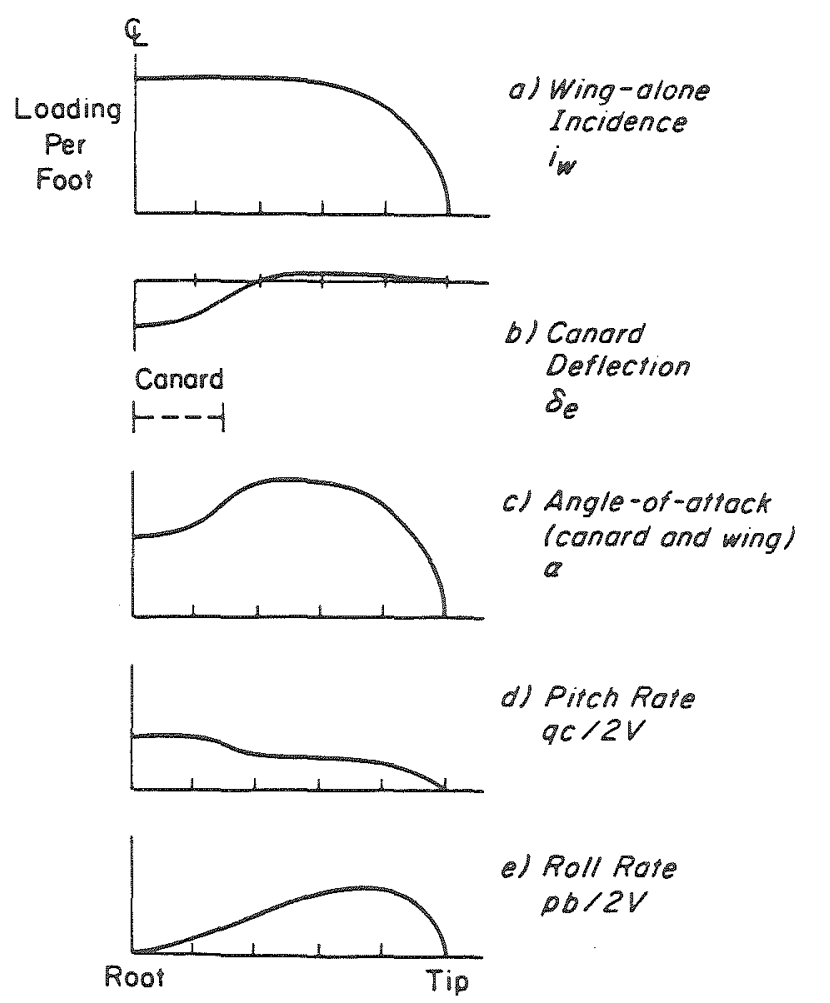

Figure 11. Load Distributions Calculated With Vortex Lattice Theory 